\title{
Critical evaluation of biodegradable polymers used in nanodrugs
}

This article was published in the following Dove Press journal:

International Journal of Nanomedicine

18 August 2013

Number of times this article has been viewed

\section{Edgar Marin ${ }^{1-3}$ \\ Maria Isabel Briceño \\ Catherina Caballero- \\ George'}

'Unit of Pharmacology, Center of Biodiversity and Drug Discovery, Institute of Scientific Research and High Technology Services, ${ }^{2}$ Nano Dispersions Technology, Panama, Republic of Panama; ${ }^{3}$ Department of Biotechnology, Archaria Nagarjuna University, Guntur, India
Correspondence: Catherina CaballeroGeorge

Institute of Scientific Research and High Technology Services, Building 219 City of Knowledge, Clayton, PO 0843-0I I03, Panama, Republic of Panama

Tel +5075I70700

Fax +5075170701

Email c.caballerogeorge@gmail.com
Abstract: Use of biodegradable polymers for biomedical applications has increased in recent decades due to their biocompatibility, biodegradability, flexibility, and minimal side effects. Applications of these materials include creation of skin, blood vessels, cartilage scaffolds, and nanosystems for drug delivery. These biodegradable polymeric nanoparticles enhance properties such as bioavailability and stability, and provide controlled release of bioactive compounds. This review evaluates the classification, synthesis, degradation mechanisms, and biological applications of the biodegradable polymers currently being studied as drug delivery carriers. In addition, the use of nanosystems to solve current drug delivery problems are reviewed.

Keywords: biodegradable polymers, nanoparticles, drug delivery, cellular uptake, biomedical applications

\section{Introduction}

The use of biodegradable polymers for biomedical applications is continually increasing and evolving. ${ }^{1-5}$ The present work reviews the most recent literature on the characteristics, properties, and applications of biodegradable polymers already in use or under investigation as drug nanocarriers.

The main advantage of biodegradable polymers is that the products of degradation are not toxic or are completely eliminated from the body by natural metabolic pathways ${ }^{6,7}$ with minimal side effects. ${ }^{8-12}$ These degradation products define the biocompatibility of a polymer. ${ }^{13-15}$ For example, poly(lactic-co-glycolic acid) (PLGA), poly(glycolic acid) (PGA) and poly(lactic acid) (PLA) have been approved by the US Food and Drug Administration (FDA) for certain medical applications, because their products of degradation are eliminated from the body in the form of carbon dioxide and water. ${ }^{13}$ Nevertheless, these polymers may reduce local $\mathrm{pH}$, affecting the integrity of the cells in their microenvironment, thus limiting their application in tissue scaffolds. Biodegradable polymers can be of natural origin or "biopolymers" produced by living organisms during the cell growth cycle. ${ }^{4,16}$ They can also be manufactured, which is another advantage of these materials because they show great synthesizing flexibility. ${ }^{17}$

Biodegradable polymers have the potential to become part of new medical devices with specific and unique physical, chemical, and mechanical properties, such as electrical conductivity, optical properties, chemical reactivity, and mechanical strength. ${ }^{18,19}$ The most important biomedical goal of biodegradable polymeric materials is the development of matrices to control the release of drugs into specific sites in the body. ${ }^{20}$ 
Therefore, there are nanodrugs specifically designed to carry therapeutic molecules that are directly coupled, functionalized, coated, or entrapped in devices produced by controlled manipulations of size and shape at the nanometer scale. ${ }^{21}$ Additionally, these polymeric materials have been used as orthopedic devices to replace bones or blood vessels and surgical sutures. ${ }^{22,23}$ Biodegradable polymeric materials provide a platform on which nanoscaled structures can be developed, and this property can be used in numerous medical applications, from surgical implants to binding matrices of drugs. ${ }^{24-26}$

Nanoparticles made with biodegradable polymers have been an important instrument in the treatment of neurodegenerative diseases, because of their ability to cross the blood-brain barrier and their high drug-loading capacity, ${ }^{17}$ or in the diagnosis and treatment of cardiovascular disease, because of their size, shape, and an available surface area for biomolecule conjugation. ${ }^{27}$ Because polymeric nanoparticles have the capability of long-term protection, they can preserve the integrity of drug molecules for more efficient delivery ${ }^{28}$ in the case of an unstable active compound. For example, PLGA nanoparticles can contain nitric oxide molecules using (trans-[RuCl([15]ane)(NO) $\left.]^{2+}\right)$ as a nitric oxide donor, ${ }^{29}$ PLGA-poly(ethylene glycol) (PEG) protect curcumin from macrophages, ${ }^{30}$ and $\mathrm{PEG}$ reduces the toxicity and increases the stability of gold nanoparticles. ${ }^{31}$

Biodegradable polymeric nanoparticles influence the pharmacokinetic behavior of drugs by fine-tuning release, like the sustained release of nerve growth factor encapsulated in polyphosphoesters. ${ }^{32}$ Some biopolymers degrade in specific $\mathrm{pH}$ environments, like paclitaxel poly $(\beta$-amino ester) nanoparticles which dissolve in the intracellular $\mathrm{pH}$ range of $5.1-6.5 .^{33}$

Thus, convenient characteristics of nanoparticles can be achieved by combining different polymers. For instance, PLGA provides a hydrophobic core that is able to retain oily material, ${ }^{34}$ while $\mathrm{PEG}$ reduces the interaction with untargeted tissues, increasing specificity. ${ }^{35}$

This review begins by describing the mechanisms of synthesis and degradation of a variety of biodegradable polymers. It also discusses encapsulation techniques used to prepare nanoparticles from these polymers, their biomedical applications, cellular uptake, and factors that affect bioavailability and internalization of nanoparticles.

\section{Classification}

Biodegradable polymers can be broadly classified, according to their origin, as natural and synthetic polymers. Natural polymers are the first option in biomedicine, due to their abundance in nature and biocompatibility. However, their full exploitation has been limited because of batch-tobatch variations in properties or risk of viral infections. ${ }^{36,37}$ This is the case with parvovirus B19 infection transmitted by blood products such as fibrin, which is widely used as a surgical adhesive, hemostatic agent, and sealant. ${ }^{38}$ Synthetic polymers, on the other hand, have manufacturing flexibility and reproducibility. ${ }^{39}$

Classification of biodegradable polymers is mainly restricted to their origin. ${ }^{6,37}$ In Table 1, we include subclassifications of common polymers used or currently under study for biomedical applications. Aliphatic polyesters, such as PLA, PLGA, and PGA, are the most used synthetic polymers. ${ }^{40}$ In this review, we give emphasis to synthetic biodegradable polymers that, in our opinion, have more potential in commercial applications where process manufacture reliability and batch reproducibility are often required.

\section{Synthesis}

Table 2 shows several of the reactions involved in synthesis of these polymers, including ring opening, polycondensation, bulk synthesis, dehydrative coupling, transesterification, and polymerization.

\section{Ring opening}

Synthesis of biodegradable polymers can be done by ringopening polymerization, which is the most common synthetic pathway of most biodegradable polymers ( $\alpha$-hydroxy acids, $\alpha$-amino acids, polydepsipeptides, polyesters). ${ }^{6}$ The six-member cyclic diesters, such as glycolide, L-lactide, and D,L-lactide, are used to synthesize PGA, poly(L-lactic acid), and poly(D,L-lactic acid), respectively by this method. For example, the production of poly(ester amide) starts with synthesis of 6-methylmorpholine-2,5-dione by heating of N-(2-bromopropionyl) glycine sodium salt. Ring-opening polymerization is then carried out in the bulk at $130^{\circ} \mathrm{C}$ for 28-48 hours using stannous octoate [ $\mathrm{Sn}(\mathrm{Oct}) 2]$ as a catalyst (Table 2A). ${ }^{41}$

\section{Polycondensation}

Biodegradable polymers can also be synthesized by polycondensation (Table 2B), which is a condensation reaction between polymeric molecules. ${ }^{42}$ Ring-opening of cyclic diesters, selfpolycondensation of hydroxy acids, or polycondensation of diacids and diols, produce polyesters. ${ }^{43}$ The polycondensation technique is cheaper than open ring polymerization and has several variants, including melt polycondensation, interfacial polycondensation, solution polycondensation, and solid/ 
Table I Data on biodegradable polymers based on natural and synthetic origin

\begin{tabular}{|c|c|c|}
\hline Origin & Subclassification & Examples \\
\hline \multirow[t]{28}{*}{ Synthetic } & Hydrolyzable backbones & \\
\hline & Polyesters & Poly(glycolic acid) $)^{6,50,161}$ \\
\hline & & Poly(lactic acid) ${ }^{6,50,51}$ \\
\hline & & Poly(caprolactone) ${ }^{6}$ \\
\hline & & $\begin{array}{l}\text { Poly(lactic-co-glycolic } \\
\text { acid) }{ }^{6,7,50,51}\end{array}$ \\
\hline & & Poly(butylene succinate) $)^{162}$ \\
\hline & & Poly(trimethylene \\
\hline & & (carbonate) $)^{50}$ \\
\hline & & Poly(p-dioxanone $)^{4}$ \\
\hline & & Poly(butylene \\
\hline & & terephthalate $)^{6,37,163}$ \\
\hline & Poly(ester amide)s & Hybrane $^{\circledR}$ SI $200^{43,79}$ \\
\hline & Polyurethanes & DegraPol $\left.\right|^{\circledR 45,164}$ \\
\hline & Polyanhydrides & $\begin{array}{l}\text { Poly[(carboxyphenoxy) } \\
\text { propane-sebacic acid] }]^{7,51}\end{array}$ \\
\hline & Polyphosphoesters & Poly[bis(hydroxyethyl) \\
\hline & & terephthalate-ethyl \\
\hline & & orthophosphorylate/ \\
\hline & & terephthaloyl chloride] $]^{6,7,32,51}$ \\
\hline & Carbon backbones & \\
\hline & (hydrolysis cannot occur) & \\
\hline & Poly(ortho esters) & Poly(ortho esters) $\left.\right|^{6,7}$ \\
\hline & & Poly(ortho esters) II ${ }^{6,7,48}$ \\
\hline & & Poly(ortho esters) IIII,7 \\
\hline & & Poly(ortho esters) IV $\mathrm{V}^{6,7}$ \\
\hline & $\begin{array}{l}\text { Poly(alkyl } \\
\text { cyanoacrylates) }\end{array}$ & Poly(butyl cyanoacrylate) ${ }^{6}$ \\
\hline & Polyether & Poly(ethylene glycol) ${ }^{3,51,164}$ \\
\hline & Poly(amino acids) & Tyrosine derived \\
\hline & & polycarbonate ${ }^{6,165}$ \\
\hline \multirow[t]{3}{*}{ Semisynthetic } & Microbial polyesters & Poly( $\beta$-hydroxyalkanoate)s $s^{6,166}$ \\
\hline & & Poly(hydroxybutyrate) $)^{6,166}$ \\
\hline & & $\begin{array}{l}\text { Poly(hydroxybutyrate-co- } \\
\text { hydroxyvalerate) })^{50,166}\end{array}$ \\
\hline \multirow[t]{10}{*}{ Natural } & Proteins & \\
\hline & Animal source & Collagen ${ }^{6,7,37}$ \\
\hline & & Albumin $6,7,37$ \\
\hline & Vegetable source & Gluten $^{63}$ \\
\hline & Polysaccharides & \\
\hline & Animal source & Chitosan $^{6,7}$ \\
\hline & & Hyaluronate $e^{37}$ \\
\hline & Vegetable source & Cellulose ${ }^{37}$ \\
\hline & & Alginate ${ }^{6,37,167}$ \\
\hline & & Starch $^{6,7}$ \\
\hline
\end{tabular}

liquefied state polycondensation. ${ }^{43}$ However, this method is hampered by difficulty in obtaining high molecular weight polymers, achievement of specific end groups, and preparation of well defined copolyesters. ${ }^{44}$

\section{Bulk synthesis}

As mentioned before, open ring polymerization is the most important method for synthesis of biodegradable polymers, but other methods can be used. Polyurethanes can be pro-
Table 2 Different pathways involved in polymer synthesis

$\begin{array}{ll}\text { A. Ring opening } & \begin{array}{l}\text { Polyesters } \\ \text { Poly(ester amide) } s^{43} \\ \text { Polyanhydrides }\end{array} \\ \text { Polyphosphoesters }\end{array}$

duced by bulk synthesis using diisocyanate (Table 2C). The reaction occurs by dehydrating the macrodiol followed by addition of $4,4^{\prime}$-diphenylmethane diisocyanate under a nitrogen atmosphere. The resulting polymer is precipitated in water and then vacuum-dried. ${ }^{45,46}$

\section{Dehydrative coupling}

Polyanhydrides are synthesized by dehydrative coupling of carboxyl groups (Table 2D). This reaction occurs by the conversion of the carboxyl group to a mixed anhydride with acetic acid. The prepolymer is then subjected to melt polycondensation. Thereby, generation of high molecular weight species is limited by reversible thermal depolymerization. In addition, acetic anhydride reflux may be unsuitable for heat-sensitive monomers. ${ }^{47}$

\section{Synthesis of poly(ortho esters)}

Poly(ortho esters) (POE), consisting of a family of four members, can be produced as follows: POE I can be synthesized by transesterification between a diol and diethoxytetrahydrofuran; POE II can be synthesized by the reaction of diketene acetal 3,9-bis(ethylidene-2,4,8,10-tetraoxaspiro[5] undecane) (Table 2E); and POE III can be synthesized by polymerization of a triol with an ortho ester, whereas POE IV is a modification of POE II by hydrolysis of the ortho ester linkage. ${ }^{48}$

\section{Mechanisms of degradation}

As mentioned before, the degradation of biodegradable polymers may lead to complete elimination of degradation products from the organism. Since the products of 
polymer degradation can produce alterations in a cell, such as inflammatory responses, ${ }^{14}$ the biocompatibility of the biodegradable polymer is defined by these degradation products. $^{49}$

The mechanisms of degradation for different polymers depend on the chemistry, molecular weight, and morphology of each type of polymer, and environmental factors such as $\mathrm{pH}$ or temperature also play an important role. Degradation occurs mainly by hydrolysis, oxidation, or enzymatic reactions. ${ }^{37,50}$

The stability of the polymeric material affects its efficiency. ${ }^{49,51}$ Therefore, knowledge about its mechanisms of degradation is crucial to select a polymer for specific applications. The most important mechanisms of polymeric degradation are discussed below.

\section{Hydrolytic degradation}

The hydrolytic mechanism involves reaction of vulnerable bonds in the polymer with water molecules, resulting in reduction of the main or side chains in the polymer. This reaction is a second order nucleophilic substitution, in which the rate of the reaction is proportional to the concentration of water and hydrolytic bonds of the polymer. Chemical groups that react with water and contain $\mathrm{O}, \mathrm{N}, \mathrm{S}$, or $\mathrm{P}$ give a positive charge to the nearby carbon atom. ${ }^{15}$

The hydrolytic activity depends mainly on the charge value of the reacting carbon atoms, but factors such as conjugate structures, side groups, and dielectric constant or water solubility also affect the hydrolytic activity of the polymer. In polyanhydrides, for example, degradation depends on the backbone of the polymer, and the relationship between the hydrophilic and hydrophobic components can be adjusted to regulate degradation. This condition is possible due to the two hydrolysable sites (Table 3 , structure 7 ) of the repeating unit. ${ }^{50}$

Polymers with hydrolysable backbones, ie, polyesters, polyamides, polyurethanes, and polyanhydrides, are susceptible to hydrolytic biodegradation under particular conditions. In aliphatic polyesters, for instance, the rate of degradation is more related to water accessibility into the matrix rather than the intrinsic rate of ester cleavage. Graft copolymerization affects reduction of the polymeric main and side chains, for instance, polymers such as PLA, which display improved biodegradability and thermal stability when grafted onto chitosan. Copolymerization can reduce the degradation rate, but also increases it. Hydrolytic cleavage degradation of poly(ester amides) can be enhanced by incorporating amino acid units into the polymers. ${ }^{50}$
Polymer degradation causes erosion of the matrix. If penetration of water into the polymer matrix produces a homogeneous erosion of the material, the behavior is called bulk erosion. On the other hand, if erosion of the material represents a mass loss in the surface while the bulk remains intact, degradation is termed surface erosion. ${ }^{50} \mathrm{~A}$ four-step mechanism for degradation of PGA in a buffer solution has been proposed elsewhere. ${ }^{52}$ Water is initially absorbed into the sample, followed by polymer molecular weight reduction throughout the sample. As soon as a critical molecular weight is reached, the polymer starts to diffuse from the surface and finally a combination of water diffusing into the polymer structure and polymer erosion on the surface causes complete degradation. ${ }^{52}$

\section{Oxidation}

The inflammatory response of cells like leukocytes and macrophages produces reactive oxygen species such as nitric oxide, hydrogen peroxide, or superoxide. These species cause degradation of polymers. ${ }^{49}$ Some biopolymers, such as polyethylene, polyether, and polyurethanes, are more suitable to degradation by an oxidation reaction, because their structure can easily generate free radicals. On the other hand, polyesters and silicon are less susceptible to oxidation. ${ }^{15,53}$ This kind of degradation follows the general mechanism shown in Figure 1: initiation of free radicals generated by inflammatory cells or by thermal, photochemical, and radiation processes; proliferation of free radicals by a series of reactions with oxygen; the free radicals produced react with the polymer and are transferred to different regions of the polymer chain; and finally, cleavage of the polymeric chain at the free radical site forms shorter segments. ${ }^{15}$ A block copolymer of PEG/ poly(propylene sulfide)/PEG that self-assembles to form nanosized vesicles has been developed. ${ }^{54}$ The mechanism consists of oxidation of central block sulfide moieties to sulfoxides and ultimately sulfones, increasing the hydrophilicity of the initially hydrophobic central block. ${ }^{54}$

\section{Enzymatic degradation}

On the other hand, enzymatic degradation involves hydrolysis catalyzed by enzymes known as hydrolases, such as proteases, glycosidases, and phosphatases. This mechanism follows surface erosion, in that the polymers lose material from the surface because the enzyme cannot penetrate into the polymer. Enzymatic degradation is affected by factors such as interactions with the polymeric chain (diffusion or adsorption of the enzyme), physicochemical properties of substrates (molecular weight, 
Table 3 Summary of chemical and biotechnologic properties of polymers used in drug delivery

\begin{tabular}{|c|c|}
\hline Structure & Properties \\
\hline 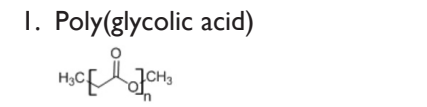 & $\begin{array}{l}\text { - Used as a matrix for controlled drug delivery and degradable sutures } \\
\text { - Insoluble in organic solvents with high melting point }{ }^{52}\end{array}$ \\
\hline 2. Poly(lactic acid) & - Used in micelles of poly(ethylene glycol) to solubilize anticancer drugs ${ }^{168}$ \\
\hline $\begin{array}{l}\text { 3. Poly(caprolactone) } \\
\\
\mathrm{H}_{3} \mathrm{C}\left(\mathrm{C}_{5}^{\mathrm{N}} \mathrm{O}_{n}^{\mathrm{CH}_{3}}\right.\end{array}$ & $\begin{array}{l}\text { - Semicrystalline polymer with slow degradation rate } \\
\text { - Drug delivery systems have been developed using biodegradable scaffolds } s^{7,169}\end{array}$ \\
\hline 4. Poly(lactide-co-glycolide) & $\begin{array}{l}\text { - Used as a matrix for controlled drug delivery } \\
\text { - Mechanical and degradation properties can be tailored depending on the copolymer ratios }{ }^{4,7}\end{array}$ \\
\hline 5. Poly(ethylene glycol) & - Most used biodegradable polymer for medical applications \\
\hline & $\begin{array}{l}\text { - Possesses flexibility, high aqueous solubility, and high circulation time } \\
\text { - Enhances drug activity } 35,113,116\end{array}$ \\
\hline $\begin{array}{l}\text { 6. Poly(ortho ester) II } \\
{ }_{3}^{\mathrm{H}_{3} \mathrm{C}} \mathrm{F}_{\mathrm{O}} \mathrm{O}_{\mathrm{O}}^{\mathrm{O}} \mathrm{X}_{\mathrm{O}}^{\mathrm{O}} \mathrm{O}_{\mathrm{CH}}^{\mathrm{C} \mathrm{CH}_{3}}\end{array}$ & $\begin{array}{l}\text { - Poly(ortho esters) consist of four-membered family of polymers; POE I, POE II, POE III, and POE IV } \\
\text { - Used in controlled drug delivery } \\
\text { - Degradation by erosion due to its hydrophobicity } \\
\text { - Very stable under physiologic conditions } s^{7,170}\end{array}$ \\
\hline $\begin{array}{l}\text { 7. Poly[(carboxyphenoxy)propane- } \\
\text { sebacic acid] }\end{array}$ & $\begin{array}{l}\text { - Used in controlled drug delivery } \\
\text { - Degradation by surface erosion } \\
\text { - Produces minimal inflammatory reaction }{ }^{7,171}\end{array}$ \\
\hline 8. Poly (alkyl cyanoacrylate) & $\begin{array}{l}\text { - Used in drug delivery } \\
\text { - Has negative surface charge } \\
\text { - Has low toxicity } \\
\text { - Easy to prepare } \\
\text { - Polymerization requires a pH below } 3.5^{64}\end{array}$ \\
\hline 9. Desaminotyrosyl octyl ester & $\begin{array}{l}\text { - Enhances the penetration of lipophilic molecules into the skin } \\
\text { - Forms stable complexes with anticancer drugs } \\
\text { - Retains the biological activity of drugs in in vitro studies }{ }^{165}\end{array}$ \\
\hline 10. Polyphosphoesters & - Suitable for controlled release of drugs \\
\hline 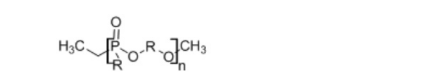 & $\begin{array}{l}\text { - Good tissue compatibility and minimal lymphocyte or macrophage activity } \\
\text { - Degradation by hydrolysis or enzymatic cleavage of the phosphate in the polymer chain }{ }^{32}\end{array}$ \\
\hline 11. Polyester amides & $\begin{array}{l}\text { - Used in controlled drug delivery, hydrogel formulations, and tissue engineering, and as adhesive material } \\
\text { - Provides good mechanical and thermal characteristics }{ }^{43}\end{array}$ \\
\hline 12. Polyurethanes & $\begin{array}{l}\text { - Widely used in biomedical applications such as heart valves, cardiac catheters, scaffolds, ligament } \\
\text { reconstructions, controlled-release drug systems }{ }^{46}\end{array}$ \\
\hline 13. Chitosan & $\begin{array}{l}\text { - Used in controlled drug release and scaffolds } \\
\text { - Has a cationic character based on its primary amino groups, and can be cross-linked using several cross- } \\
\text { linking agents }{ }^{172,173}\end{array}$ \\
\hline
\end{tabular}

Note: *Hydrolyzable sites.

Abbreviation: POE, poly(ortho ester).

surface area), properties of the enzyme, environmental conditions ( $\mathrm{pH}$, temperature), and presence of activators or inhibitors in the medium. ${ }^{49}$ For example, rapid swelling and enzymatic degradation of starch reduces its applications in controlled delivery. However, acetylation of starch reduces its enzymatic degradation, improving its potential as a carrier system. ${ }^{55}$

The enzymatic hydrolysis of chitosan-grafted PEG and chitosan nanoparticles has been studied using lysozyme, a $14 \mathrm{kD}$ cationic protein that catalyzes hydrolysis of the 1,4- $\beta$-linkages between $\mathrm{N}$-acetylmuramic acid and $\mathrm{N}$-acetylD-glucosamine. It was demonstrated that nanoparticles made of chitosan showed more enzymatic degradation as compared with nanoparticles made of chitosan-grafted PEG; this reduction in degradation rate can be attributed to the presence of PEG.$^{30}$ Figure 2 shows a nanosphere of chitosan-grafted-PEG with the active component inside the nanoparticle core. 


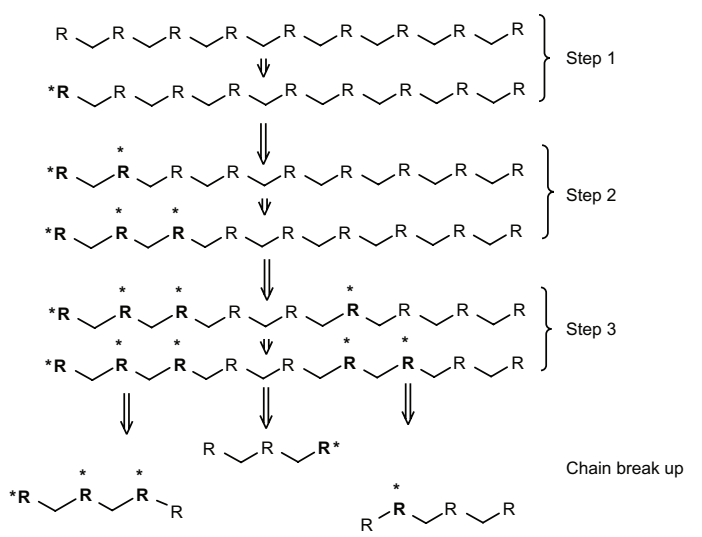

Figure I Scheme of general mechanism of oxidation reaction. Step I is an initiation that involves generation of free radicals. Step 2 (proliferation) is an increase in the number of free radicals by a series of reactions with oxygen in the surrounding polymer. Step 3 is a transfer of free radicals to different sites in the polymer chain. Finally, the break-up occurs, leading to formation of new chain ends.

Notes: R: Polymer chain. *Free radical.

\section{Strategies to control drug delivery}

Controlled degradation of polymers helps to maintain drug levels within a suitable therapeutic window, ${ }^{6}$ and since different drugs require different release systems, polymeric matrices must be carefully engineered for a specific drug and a specific target. ${ }^{6}$ For instance, unmodified chitosan nanoparticles of ammonium glycyrrhizinate showed a burst effect followed by a continuous release profile, ${ }^{56}$ while modified chitosan/alginate enabled $\mathrm{pH}$-dependent release of insulin after oral administration. ${ }^{57}$

As mentioned earlier, understanding of the degradation mechanisms of a material plays a crucial role in the efficacy of a drug delivery device. The polymeric matrix has to degrade under physiologic conditions in a controlled manner to allow sustained release of the drug. ${ }^{51}$ The two main strategies for controlled drug delivery are classified as temporal (Figure 3) or targeted (Figure 4) drug delivery systems. ${ }^{6,49,51}$

A temporal delivery system looks for the extended release of drugs or their release in a specific period of time. This mechanism allows the concentration of the drugs in the body to be maintained at a constant level, thereby reducing the frequency of administration. It also protects the molecule from the environment and ensures maximum benefits from the drug. ${ }^{51}$ Temporal release delays diffusion of the molecule out of the polymeric matrix, inhibiting diffusion or controlling drug flow through the matrix. ${ }^{51}$ These strategies involve manipulation of some physicochemical properties of the polymers, eg, copolymerizing or blending of polymers in order to change the degradation behavior.

Chitosan/glyceryl monooleate has been used to form paclitaxel-loaded nanoparticles with high entrapment efficiency (98\%) and increased mucoadhesive properties. These nanoparticles have a hydrophilic surface and a hydrophobic core, and also have a significant positive charge and sustained-release characteristics. These characteristics intensify the cellular association of paclitaxel and expand the duration of the therapeutic effect of the drug. Delivery starts with a burst release probably due to the tendency of chitosan to swell, followed by slow release. Dose-response studies show that nanoparticles increased MDA-MB-231 cell death when compared with paclitaxel solution alone. ${ }^{58}$

A targeted drug delivery system is designed to seek a specific site of action in the body. ${ }^{6}$ This mechanism avoids two main situations, ie, side effects caused by drugs in contact with untargeted tissue and drug loss due to natural distribution in the body. ${ }^{51} \mathrm{~A}$ taxane-loaded PGA-PEG nanoparticle conjugated to the A10 RNA aptamer, which binds to prostatespecific membrane antigen, has been developed. This nanoparticle shows enhanced delivery to tumor cells compared

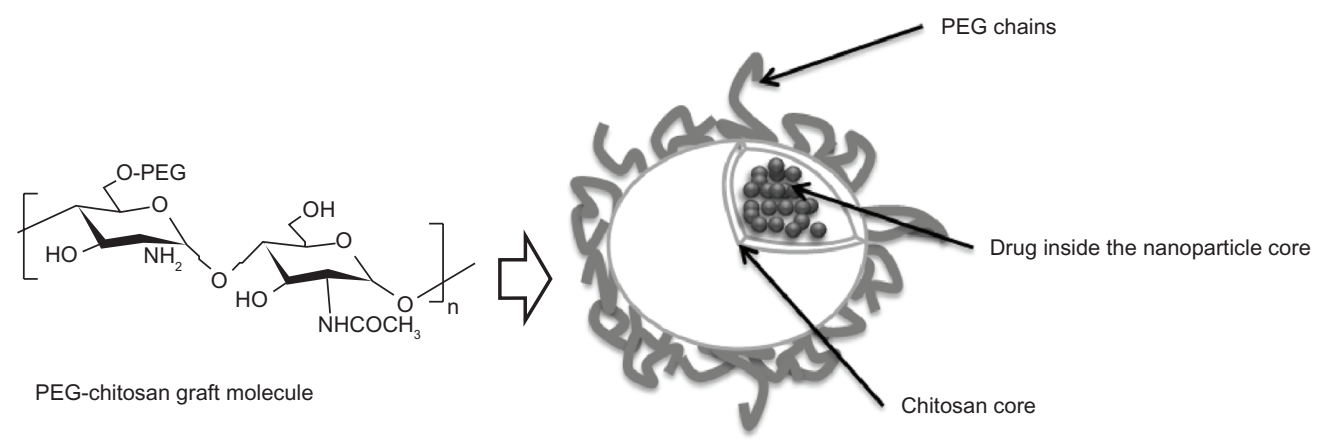

Figure 2 Scheme of a chitosan nanosphere with grafted PEG. Due to its biodegradability, biocompatibility, and minimal toxicity, chitosan and PEG have been used to develop nanoparticle carrier systems for poorly soluble drugs. The chitosan core can encapsulate drugs, allowing for their subsequent sustained release.

Abbreviation: PEG, poly(ethylene glycol). 
A

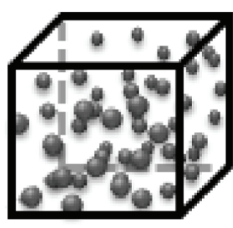

Dissolution

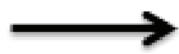

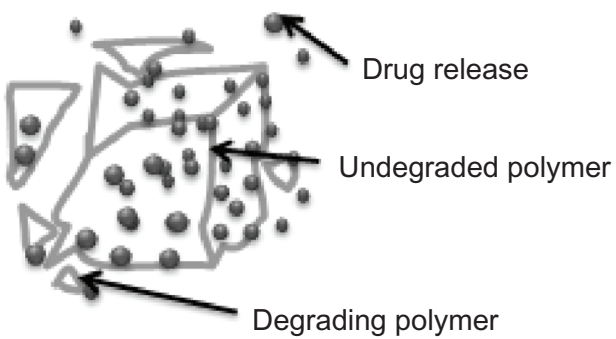

Degrading polymer

Diffusion

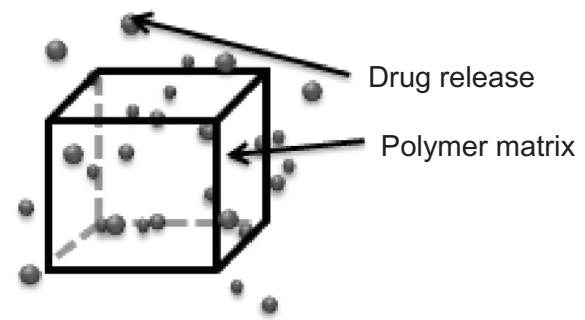

C

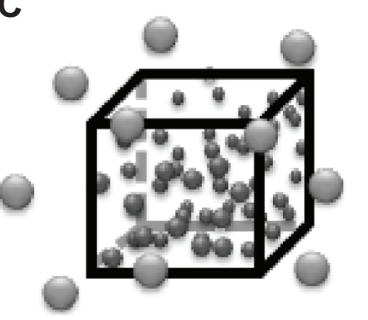

Flow control

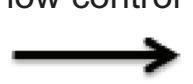

c

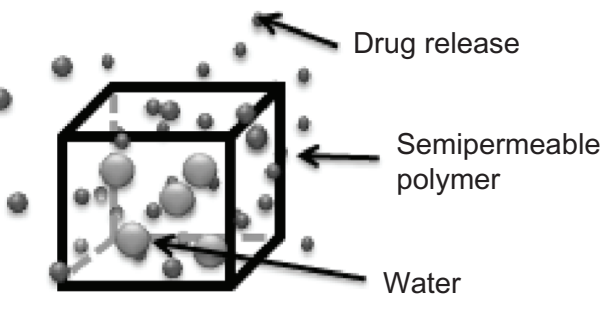

Figure 3 Mechanisms for temporal controlled-release drug systems. (A) Dissolution of a polymer with slow break-down that delays exposure of drug to water from the environment of the delivery system. (B) Drug diffusion-controlled release through gaps in insoluble polymeric devices. (C) Controlled flow using osmotic forces on a semipermeable polymer matrix.

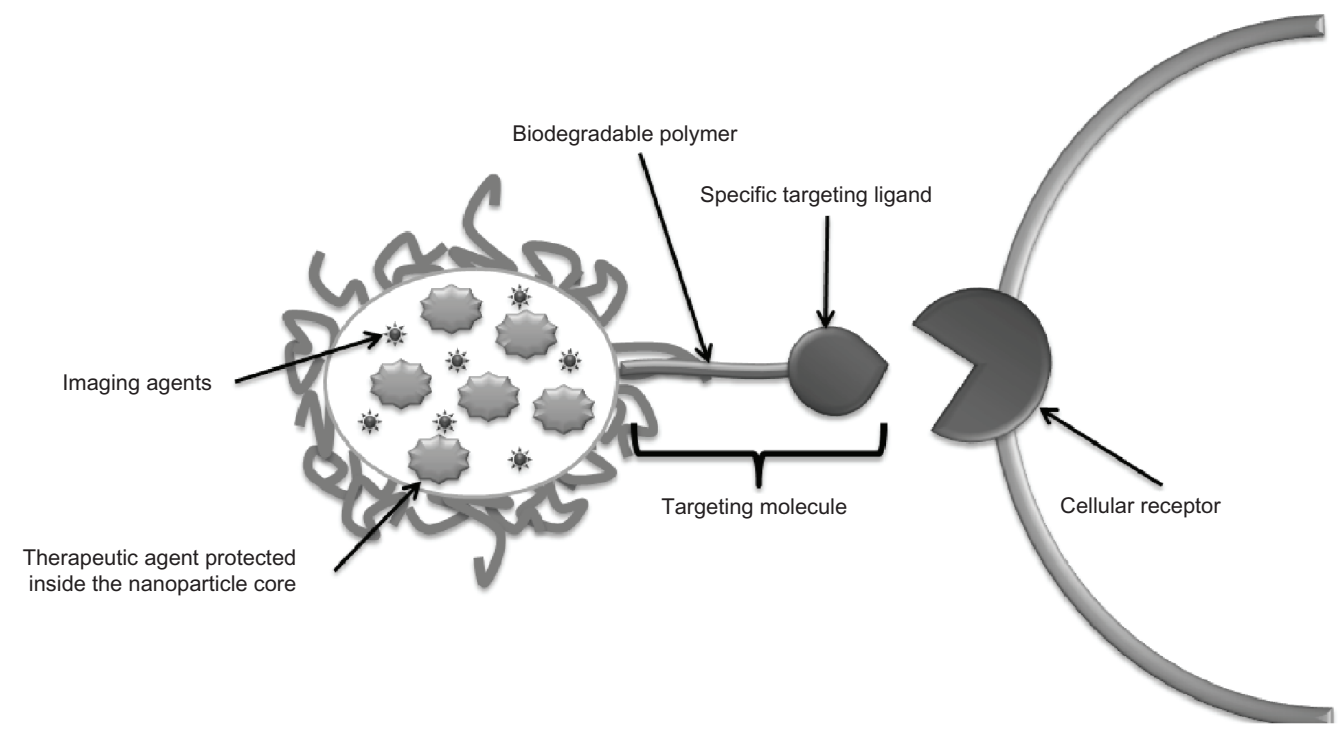

Figure 4 Strategy to create targeted drug delivery systems. Therapeutic tools like genes, proteins, and small drug molecules, as well as imaging tools such as fluorescent probes or magnetic contrast agents are encapsulated inside the nanoparticle core. In parallel, targeting molecules like specific antibodies or recognition peptides are located on the nanoparticle surface. 
with the equivalent nanoparticles lacking the aptamer. The ability of conjugated nanoparticles to maintain a significantly higher concentration in the cell is due to uptake by the targeted ligand. ${ }^{59}$ Surface modification of the polymeric matrix by addition of enzymatic recognition sites modulates the degradation rate or cellular uptake of the nanoparticle (eg, by means of receptor-mediated gene delivery) enhancing the transfection efficiency. ${ }^{60}$ Thus, the transfection efficiency of DNA was improved using a folic acid-conjugated stearic acid-grafted chitosan/pDNA complex in SKOV3 cells. ${ }^{60}$

\section{Encapsulation techniques}

Several techniques have been developed to encapsulate drugs using biodegradable polymers in the last 60 years. The major aim of these techniques is to protect active compounds from environmental deterioration and to obtain controlled drug release. ${ }^{20,61}$ These techniques are classified according to the initial state of the polymer into two main categories, ie, nanoparticles obtained from polymerization of a monomer or nanoparticles obtained from a macromolecule.

The polymerization of a monomer to produce nanoparticles is a fast and easily scalable method, with high entrapment efficiency. However, residual molecules in the medium (surfactant, monomer) can be toxic and require extensive purification of the nanoparticles. ${ }^{62}$

\section{From polymerization of a monomer Emulsion polymerization}

Emulsion polymerization is a technique that can be classified according to continuous phase as organic or aqueous emulsion polymerization. ${ }^{62}$ For instance, polymerization of poly(alkyl cyanoacrylate) monomers is a process in which drops of hydrophobic monomers are emulsified in the aqueous phase, and usually requires a $\mathrm{pH}$ below 3.5 and constant stirring. Polymerization is confined to the surface of the micelle due to the high ionic strength of the medium. ${ }^{63,64}$ Initialization can occur by clash with an initiator (ion or free radical) or radiation of the monomer molecule. Continuous organic phase methodology may involve toxic organic solvents, surfactants, monomers, and initiators, which represents a disadvantage for biomedical applications. ${ }^{62}$

\section{Interfacial polymerization}

Interfacial polymerization involves introduction of an alcohol solution of the monomer into an aqueous solution containing surfactants and ions that induce polymerization. ${ }^{62,65}$ This method has some advantages, such as high efficiency of hydrophilic drug encapsulation (up to $90 \%$ ) and spontaneous polymer-nanoparticle formation. ${ }^{62}$ For instance, nanoparticles of poly(n-butylcyanoacrylate) with diameters of $132 \mathrm{~nm}$ prepared by interfacial polymerization have shown excellent transdermal penetration. The major disadvantage of this technique is the use of organic solvents in the continuous phase. ${ }^{65}$

\section{Polycondensation}

Polycondensation starts with formation of an oligopolymer membrane at the interface of the oil or water droplet in the emulsion. The inner phase formed through the condensation reaction in the core is forced away from the reaction site, followed by growth of the polymer membrane. ${ }^{66,67}$ Polymeric nanoparticles of polysaccharides with a size range of 200$300 \mathrm{~nm}$ have been produced using this method. ${ }^{68}$

\section{From macromolecules}

\section{Emulsion solvent evaporation}

This method involves two steps; the first one is formation of an emulsion in a dispersed organic phase containing dissolved polymers in an aqueous phase while constantly stirring. The final step is gradual evaporation of the solvent under low pressure to dry the particles. ${ }^{62}$ The modified solvent evaporation method allows production of porous polylactide microspheres that can be aerosolized more easily than nonporous ones, increasing the breathable fractions of inhaled particles. In addition, these particles can maintain overall particle volume while reducing acidic degradation products. These properties allow for diverse medical applications, such as engineering scaffold tissue, drug delivery carriers, and adsorption matrices. ${ }^{69}$ Emulsion solvent evaporation appears to be appropriate for laboratory conditions, but is not suitable for large-scale production. ${ }^{70}$

\section{Salting out}

This method consists of separation of water-miscible solvents from aqueous solution by the salting out effect. It provides less stress to protein drugs, ${ }^{71}$ and allows use of a wide selection of solvents to produce drug nanoparticles. This solvent variation affects particle size, as well as the porosity and roughness of the nanoparticle. ${ }^{72}$ A solution of polymer, drug, and a solvent, normally acetone, is emulsified into an aqueous solution that contains a salting-out agent and a colloidal stabilizer. The salting-out agent can be an electrolyte such as calcium chloride, magnesium acetate, or a nanoelectrolyte such as sucrose. This agent may compete for water of hydration causing phase separation. ${ }^{73}$ The result of acetone dilution into water is formation of nanoparticles, followed by 
solvent and salting-out agent elimination via cross-flow filtration. This is an easy procedure for encapsulation of drugs. However, it is only suitable for loading lipophilic drugs and requires several washing steps. ${ }^{62}$

\section{Emulsion/solvent diffusion}

This method is very similar to the salting-out technique. In this case, the polymer is dissolved into an organic solvent (partially miscible with water), and the solution is saturated with water in order to reach an initial thermodynamic equilibrium between water and the organic phase. The nanoparticles are formed by solvent diffusion into the aqueous phase. ${ }^{62}$ A modified emulsion/solvent diffusion method was used to produce PLGA nanoparticles (280-292 nm). The modified method can produce PLGA nanoparticles with a simple preparation scheme, in which the mixture of water-miscible organic solvent prevents nanoparticle aggregation. ${ }^{74}$

\section{Supercritical fluids}

This is a widely applied technique, ${ }^{75-78}$ using the advantageous and exceptional thermodynamic, heat-transfer, and mass-transfer transport properties of supercritical fluids. ${ }^{79}$ They have gas-like viscosity and higher diffusivity than traditional solvents, and the density can be tuned by a change in pressure. However, use of this technique is limited due to the poor solubility of high molecular mass $(10,000)$ polymers $^{20}$ and difficulty in dissolving strong polar substances in supercritical $\mathrm{CO}_{2}{ }^{62} \mathrm{~A}$ supercritical fluid technique was used to produce 5-aminosalicylic acid nanoparticles via a method in which the particle size and morphology could be tuned by adjusting parameters such as concentration, solution flow rate, or temperature. The solution flow rate significantly affected drug loading and entrapment efficiency. ${ }^{19}$

\section{Solvent displacement}

Using this procedure, drugs and polymers are dissolved in a water-miscible solvent. Next, the organic solution is injected into an aqueous solution under stirring. Nanoparticles are formed immediately by solvent diffusion. The organic solvent is then eliminated from the suspension under reduced pressure. The major disadvantage of this technique is finding a drug/polymer/solvent/nonsolvent system in which nanoparticles can be formed with efficient entrapment of the drug. Furthermore, this method is not advantageous for encapsulation of water-soluble drugs, due to the fast diffusing rate from the organic phase into the water phase. ${ }^{62}$ However, a modified method has been developed to make $300 \mathrm{~nm}$ Gantrez ${ }^{\mathrm{TM}}$ nanoparticles (poly[methyl vinyl ether-co-maleic anhydride]) with encapsulated ovalbumin which were able to increase antibody titers (immunoglobulins $\mathrm{G} 1$ and $\mathrm{G} 2 \mathrm{a}$ ) in mice. ${ }^{80}$

Nanoparticles must be free of contaminants for biomedical application. The main processes for nanoparticle purification include ultracentrifugation, dialysis, gel filtration, and cross-flow filtration. ${ }^{62,81}$

Moreover, chemical factors such as $\mathrm{pH}$ can destabilize the system, ${ }^{82}$ while physical variables such as storage temperature, Brownian motion, and gravitational forces can produce aggregation, diffusion, or sedimentation of the colloidal particles. ${ }^{82}$ A suitable stabilizer or surfactant can be used in order to prevent aggregation or sedimentation phenomena. ${ }^{83}$

The physical and chemical stability of nanoparticles can be improved by elimination of water. ${ }^{62}$ The most common method used is freeze-drying or lyophilization. ${ }^{82}$ Thereby, the nanoparticle suspension can be primarily frozen followed by elimination of water via sublimation. ${ }^{62,82}$ Use of a cryoprotectant such as glucose, sucrose, sorbitol, maltose, gelatin, or mannitol is important to avoid changes in the nanoparticles during the freezing step. ${ }^{82}$ Finally, nanoparticles can be stored at room temperature, but some studies have shown that the best long term-storage is achieved by refrigeration at $4^{\circ} \mathrm{C} .^{82,84}$

\section{Biomedical applications}

The main goal of nanotechnology as applied in medicine corresponds to use of engineered materials that facilitate interaction of drugs with their biological targets while minimizing side effects. ${ }^{17}$ In order to use a biodegradable polymer in biomedicine, its degradation products must be nontoxic and should be easily eliminated from the body. ${ }^{15}$ Meanwhile, biodegradable polymeric nanoparticles have been used in scaffolds to promote tissue regeneration. ${ }^{85,86}$ Most frequently, they serve as delivery systems for drugs used in the treatment of cancer and neurodegenerative disorders, as antimicrobials, antivirals, and immunosuppressants, and more recently have been used in cardiovascular disease and osteoporosis. ${ }^{39,87-89}$

\section{Cancer}

The toxicity of cytostatic drugs is not confined to malignant cells, so it is desirable to encapsulate them in target-specific controlled-release polymers. ${ }^{89}$ Nanoparticles provide better penetration of therapeutic substances within the body at a reduced risk and could diminish the multidrug resistance that characterizes many anticancer drugs. ${ }^{90}$ 
Among the various biodegradable synthetic and natural polymers used to prepare nanoparticles for delivery of anticancer agents, PLA, PLGA, and poly(caprolactone) are the most often used. ${ }^{90}$ For example, paclitaxel-loaded PLGA nanoparticles with antibodies capable of epithelial cell adhesion have been developed ${ }^{91}$ It was demonstrated that paclitaxel-loaded nanoparticles equipped with such antibodies enhanced cellular uptake compared with nanoparticles without the ligand. Additionally, nanoparticles with epithelial cell adhesion capability showed increased antiproliferative activity of paclitaxel.

Moreover, multidrug resistance, which characterizes many anticancer drugs, like docetaxel, was overcome by docetaxelloaded polycaprolactone/Pluronic F68 nanoparticles. Such nanoparticles increased the level of uptake of this drug in a docetaxel-resistant human breast cancer cell line. ${ }^{90}$

Cisplatin-based therapeutic regimens have been limited by severe side effects and toxicity to organs, including the liver, kidney, heart, and nervous system. Nanosized drug carriers have been developed to minimize the side effects of cisplatin and enhance its antitumor efficacy through the form of polymeric micelles, liposomes, and solid lipid nanoparticles during cancer therapy. However, the encapsulation efficiency of cisplatin is still poor. ${ }^{34}$

Carboxymethyl cellulose core nanoparticles made from PLGA-monomethoxy-PEG copolymers and d-alpha tocopheryl polyethylene glycol 1000 succinate as an emulsifier are homogeneous nanoparticles devoid of debris and aggregation, that enhance the loading efficiency of cisplatin. Hepatic necrosis and atrophy in the kidney in mice treated with free cisplatin has been observed, but not in mice treated with cisplatin-loaded nanoparticles. Further, organs such as the heart, spleen, and lungs did not show any abnormalities. ${ }^{34}$

\section{Neurodegenerative disorders}

Neurodegenerative disorders are mostly recognized to be Alzheimer's disease and Parkinson's disease. Their treatment remains a major challenge, since drug delivery to the brain depends on the ability of the formulation to pass the numerous protective barriers surrounding the central nervous system. ${ }^{17}$ Nanotechnology provides engineered materials with functional organization on the nanometer scale, which are capable of penetrating the blood-brain barrier. ${ }^{92}$

Curcumin is a water-insoluble natural product with antiamyloid and antioxidant activity, both of which are properties recognized as being highly beneficial in the treatment of Alzheimer's disease. ${ }^{93,94}$ New formulations of curcumin attempt to target the drug towards its site of action in the brain and to overcome the problem of insolubility. Thus, a new water-soluble PLGA-coated curcumin nanoparticle has been successfully synthesized and coupled with Tet-1 peptide, giving neuron affinity to the nanoparticles. ${ }^{94}$

Other formulations designed to treat neurodegenerative disorders include chitosan nanoparticles loaded with subfragments of amyloid-beta, which permeated the blood-brain barrier and were nonimmunogenic; ${ }^{95}$ a transdermal nanoemulsion gel containing ropinirole to treat Parkinson's disease, which improved the relative bioavailability of the drug with no toxicity; ${ }^{96}$ and dopamine incorporated into a smart nanocrystal conjugated with PEG and covered by a carbohydrate shell allowing recognition of glucose transporter $1 .{ }^{97}$

Detailed reviews on current nanotechnology-based delivery systems applied to the treatment of Alzheimer's disease and Parkinson's disease have been recently published..$^{17,98}$

\section{Cardiovascular disease}

Current research on biodegradable polymers focuses on their applications in vascular tissue engineering and diagnosis (imaging), while fewer works involve nanocarriers for drug delivery. 39,99

Nanocarriers for drug delivery have been investigated for treatment of atherosclerosis and restenosis. ${ }^{27}$ A novel sustained-release drug delivery system using tacrolimus-eluting biodegradable nanofibers composed of poly(L-lactide-coglycolide) and tacrolimus was developed. This formulation reduced intimal hyperplasia and preserved endothelialization even in a venous stricture and might be useful for preventing recurrent pulmonary venous obstruction after correction of total anomalous pulmonary venous connection. ${ }^{100}$

Subsequently, localized drug delivery from drug-eluting stents has been accepted as one of the most promising treatment methods for preventing restenosis after stenting. A controlled-release formulation of epigallocatechin-3-Ogallate in PLCL-coated stents was made to suppress migration and invasion of vascular smooth muscle cells as well as platelet-mediated thrombosis. ${ }^{101}$ With this purpose, industry has also manufactured drug-eluting stents containing antiproliferative drugs like paclitaxel and sirolimus that promote integration of the stent within the vessel wall. ${ }^{27}$

\section{Microbial and parasitic infections}

Because of their nature and size, polymeric nanoparticles are easily endocytosed by phagocytic cells, which might contain the pathogen. A recent review includes an indepth description of biodegradable polymers in nanoparticles for the treatment of intracellular microbial infections. ${ }^{89}$ 


\section{Viral infections}

Numerous groups have proposed biodegradable nanoparticles and microparticles as vaccine delivery systems, aiming at induction of both humoral and cellular immune responses. ${ }^{39,102,103}$ For example, PLGA has been applied to encapsulate the hepatitis B surface antigen, ${ }^{102}$ and PEG and Pluronic-poly(ethylenimine) (PEI) has been used to formulate nanogel carriers of nucleoside reverse transcriptase inhibitors decorated with brain-targeting peptide molecules, which demonstrated high efficacy for inhibition of human immunodeficiency virus-1 in the brain. ${ }^{104}$ Another example of biodegradable nanoparticle-based vaccines is the intranasal formulation of entrapped PLGA nanoparticles with ultraviolet-killed porcine reproductive and respiratory syndrome virus antigens. ${ }^{105}$

Nanohydrogels of pure chitosan obtained by ammoniainduced physical gelation of a reverse emulsion in a triglyceride were loaded with human immunodeficiency virus-1 p24 and immunoglobulin $\mathrm{G}$ and have been proposed as versatile carriers for a variety of biomolecules. ${ }^{106}$

\section{Osteoporosis}

The problems associated with current orthopedic drug delivery systems include limited ability to reach the target site by conventional systemic administration and weak bonding of the drug with its carrier, which causes nonspecific bone formation in unaffected areas. For instance, an implantable system capable of long-term drug release of a bone morphogenetic protein derived and peptide loaded onto nanocrystalline hydroxyapatite and dispersed into PLGA was designed. ${ }^{107}$ More applications of nanohydroxyapatite have been described elsewhere. ${ }^{108}$

\section{Mitochondria-targeted drugs}

Efficient delivery of various drugs targeting mitochondria can be achieved by designing targeted nanoparticles based on blends of biodegradable polymers, such as a targeted PLGAblock-PEG-triphenylphosphonium polymer with either nontargeted PLGA-block-PEG-OH or PLGA-COOH. ${ }^{109}$

\section{Bioavailability}

Biodegradable polymers in controlled drug release systems play an important role in increasing the bioavailability of poorly soluble and unstable drugs. For instance, encapsulation in polymeric nanoparticles has improved the solubility and bioavailability of poorly water-soluble curcumin through formation of exosome-curcumin complexes. ${ }^{110}$ These results have a significant impact on target-based drug development for successful in vivo drug delivery to treat inflammationrelated diseases. Curcumin-loaded PLGA nanoparticles using PEG 5000 as a stabilizer were prepared. These curcumin nanoparticles were more bioavailable, had a substantial longer half-life than free curcumin, and were nontoxic. ${ }^{111}$

Chitosan can be used as a coating material to enhance drug bioavailability due to its absorption-enhancing effect. ${ }^{70}$ For example, the bioavailability of cyclosporin A was increased using chitosan nanoparticles. The increased gastrointestinal permeability of charged chitosan nanoparticles improves their absorption rate. ${ }^{112}$

Conjugation of PEG to a drug improves water solubility, ${ }^{113}$ stability in a specific medium such as blood plasma, ${ }^{114}$ and bioavailability. ${ }^{115}$ It also improves pharmacokinetic parameters, including volume of distribution, circulation half-life, and renal clearance, ${ }^{116}$ and also provides protection from recognition by the immune system, prolongs the circulation time, and increases the efficacy of PEGylated nanoparticles in vivo. ${ }^{115}$

\section{Cellular uptake}

The mechanism used by cells to internalize particles varies according to the characteristics of the particles. A general classification of internalization mechanisms includes passive and active transport. Passive transport involves diffusion across the membrane, in which the concentration gradient is the driving force, and osmosis, dialysis and facilitated diffusion are examples of this type of transport. ${ }^{117}$ Active transport is an energy-dependent movement across the membrane. This mechanism refers to the reversible binding of a membrane component to the material to be introduced into the cell. ${ }^{1{ }^{17}}$ Nanoparticles may cross the cell membrane by either passive transport or an active mechanism of internalization, such as endocytosis. ${ }^{117}$

Endocytosis is a complex process that includes many alternatives, the best known of which is the clathrin-mediated mechanism. ${ }^{117}$ General classifications include two main categories, ie, phagocytosis (actin-dependent process, large particle) and pinocytosis (solid and small particles). ${ }^{117}$

Phagocytosis occurs mainly in specialized mammalian cells such as macrophages, monocytes, and dendritic cells, the function of which is to maintain a clean and sterile immune system. ${ }^{118}$ The process starts with polymerization of actin, followed by particle internalization mediated by specific receptors, ie, Rho family GTPases, which trigger signaling for ingestion. ${ }^{118}$ The conventional particle size for phagocytosis starts at around $0.5 \mu \mathrm{m} .{ }^{119}$ However, some studies have shown that the optimal size range of drug carriers is between $200 \mathrm{~nm}$ and $3 \mu \mathrm{m} .{ }^{120,121}$ 
On the other hand, pinocytosis occurs in almost all cells and involves a variety of mechanisms. The most common uptake pathways are mediated by either clathrin-coated pits or caveolae. ${ }^{117}$ Descriptions of the main classes of endocytosis are discussed below.

\section{Clathrin-mediated endocytosis}

Clathrin-mediated endocytosis occurs in all mammalian cells and is mediated by specific receptors, and is a process whereby "coated pits" invaginate into the cell and form vesicles, usually with particles ranging from $60 \mathrm{~nm}$ to $200 \mathrm{~nm} .{ }^{117}$ This process occurs typically in a membrane area rich in clathrin. It has been demonstrated that encapsulation of apotransferrin can enhance uptake of curcumin-loaded nanoparticles, because endocytosis of these nanoparticles is mediated by the transferrin receptor. This transferrin receptor is implicated in clathrin-mediated endocytosis. ${ }^{122}$ There are several works describing in detail the structure of clathrin and the proteins involved in this pathway, making it possible to model the process of internalization. ${ }^{123}$ Serum-containing medium decreased the cellular uptake of $20 \mathrm{~nm}$ carboxylate polystyrene nanoparticles by 20 -fold compared with serumdeprived medium; however, in both cases, internalization occurred via clathrin-mediated endocytosis. ${ }^{124}$

\section{Caveolae-mediated endocytosis}

Caveolae-mediated endocytosis involves bag-shaped compartments in the cell membrane formed by groups of lipids called caveolae, which are capable of producing invagination after interacting with a large number of signaling-associated proteins, such as receptor tyrosine and serine/threonine kinases, G-protein coupled receptors, and steroid hormone receptors, among others. Caveolae are very common in endothelial cells and are considered the main pathway for particles above $200 \mathrm{~nm} .{ }^{125}$ This is the case of nanoparticles modified with albumin, which are internalized and further degraded by caveolae-mediated mechanisms on endothelial cells. $^{126}$

\section{Macropinocytosis}

Macropinocytosis involves the invagination of a highly ruffled area in the plasma membrane, with subsequent internalization of vesicles containing an important amount of fluid from the extracellular region. These vesicles are called macropinosomes (generally bigger than $1 \mu \mathrm{m}$ ) and have poor size selective uptake. ${ }^{127}$ This mechanism is based on Rac1 (small G proteins) and actin-dependent, and has been reported in the literature. ${ }^{117,128}$ However, the molecules implicated in the pathway are not known. Studies of the internalization pathway of $90 \mathrm{~nm}$ surface-charged PEG-PLA nanoparticles in canine kidney (MDCK type II) cells showed that a fraction of both cationic and anionic nanoparticles internalized through a macropinocytic-like pathway. ${ }^{129}$

\section{Clathrin-caveolae-independent endocytosis}

Recently, other endocytic mechanisms have been reported and classified as clathrin-caveolae-independent, ${ }^{117,130}$ showing a similar mechanism of caveolae-mediated endocytosis, ${ }^{131}$ but the complete mechanism is not as yet understood. Different cholesterol-rich microdomains are related to this pathway. The cell invaginates via a cholesterol-dependent pathway and the kinetics of internalization are different from conventional transmembrane protein uptake. The cholesterol microdomains form lipid rafts $(40-50 \mathrm{~nm})$ that diffuse through the cell surface and are internalized by endocytic vesicles rich in glycosylphosphatidylinositol anchor proteins. However, the factors regulating this mechanism are still unclear. ${ }^{117,132}$

\section{Physicochemical properties affecting cellular uptake}

Cellular uptake of nanoparticles depends on their physicochemical properties, such as size, shape, charge, and surface hydrophilicity, and the presence of a ligand at the surface. ${ }^{133-135}$

\section{Size}

Particle size can directly affect the mechanism and efficiency of cellular uptake, endocytosis, and further processing of particles in the endocytic pathway, ${ }^{117}$ with the exception of macropinocytosis, which is hardly a size-selective endocytic pathway. ${ }^{129}$

Epithelial cells can internalize nanoparticles of a diameter smaller than $100 \mathrm{~nm} .{ }^{136}$ Nonphagocytic cells can internalize nanoparticles with a lower size limit of $200 \mathrm{~nm}$ and an upper limit of $1 \mu \mathrm{m}$ via a clathrin-independent mechanism. However, these particles prefer a caveolae-mediated endocytosis pathway. ${ }^{121}$ Internalization of particles with a diameter less than $100 \mathrm{~nm}$ implies a receptor-mediated, vesicle-coated mechanism, in a relative fast process (30 minutes) ${ }^{121,131}$ that also depends on the number of receptors in the target membrane cells. ${ }^{60}$

Some studies have established behavioral patterns with regard to nanoparticle size, in that if the particle size decreases, both cellular uptake and cytotoxicity increase. ${ }^{137}$ However, nanodrugs with noninternalizing markers have shown toxicity nearby tumor cells, so it is not clear to what 
extent endocytosis can be correlated to cytotoxicity of drugs. ${ }^{35}$ Further studies suggest that the increase in cytotoxicity of the compound delivered by liposomes is probably due to a different distribution of liposomes inside the cell compartments, which improves the efficiency of activity. ${ }^{35,138}$

Toxicity of nanoparticles is also related to their size. Some studies show that the PEG-coated gold nanoparticles with a diameters of 5-10 $\mathrm{nm}$ accumulate in the liver; $30 \mathrm{~nm}$ particles accumulate preferentially in the spleen, and particles with diameters of 10-60 nm have low toxicity in the liver and kidneys. ${ }^{31}$

\section{Shape}

Internalization pathways for nanoparticles seem to depend on their shape, so endocytosis of rod-shaped polymeric nanoparticles occurs more rapidly and efficiently than that of sphere-shaped particles in nonphagocytic cells. ${ }^{120}$ This characteristic confers an advantage to nanofibers, which are recently developed drug carriers with applications in gene therapy ${ }^{139}$ and industrial synthetic chemistry. ${ }^{140}$ However, due to the multiple variables involved in internalization mechanisms (eg, shape, size, charge), no general tendency can be established as yet.

\section{Charge and hydrophilicity}

Nanoparticle charge and hydrophilicity are affected by polymer composition. ${ }^{133,141}$ Positively charged nanoparticles interact with cells by binding to the cell membrane via electrostatic interactions. ${ }^{142}$ These interactions are common in polymers such as chitosan. ${ }^{143}$ Studies using negatively charged carboxy-terminal poly(amidoamine) dendrimers have shown significant cellular uptake in a human KB carcinoma cell line. In addition, it has been determined that the surface curvature of the nanoparticles is not a factor that influences the ligand-receptor interaction, but only the charge of the nanoparticles. ${ }^{142}$ Cationic PEI nanoparticles have been used to demonstrate that charge on the surface of a nanoparticle modifies its entry through human blood brain barrier endothelial (hCMEC/D3) cells. The charge of the nanoparticle stimulates targeting into a macropinocytotic entry pathway. Additionally, it was found that nanoparticles coupled with a ligand (prion) are internalized via the caveolin 1 and clathrin pathways. ${ }^{144}$ An optimized formulation of PLGA nanoparticles coated with cationic materials increased DNA encapsulation efficiency and enhanced gene delivery to A549 lung epithelial cells. ${ }^{145}$

The surface properties of nanoparticles can be modified by adsorption of surfactants, hydrophilic stabilizing, or bioadhesive polymers on the nanoparticle surface. These surface modifications affect the properties of nanoparticles, such as zeta potential, hydrophobicity, colloidal stability, and mucoadhesion. ${ }^{145}$ It has been suggested that transport of nanoparticles through mucosal surfaces increases with the presence of hydrophilic polymers on the surface of these systems. ${ }^{133}$ Mucoadhesion extends the residence time of carrier systems in the site of action, increasing the bioavailability of poorly absorbed drugs. ${ }^{133}$ Polymers such as PEG, methylcellulose, hydroxyethylcellulose, and chitosan are examples of materials that show mucoadhesion. ${ }^{146,147}$ For instance, studies using chitosan-loaded and modified chitosan-loaded nanoparticles (chitosan- $\mathrm{N}$-acetylcysteine and $\mathrm{N}$-acetyl penicillamine-chitosan) as a drug delivery system against epidermal growth factor receptor in T47D breast cancer cells showed a high degree of stability and mucoadhesive ability. Modified chitosan nanoparticles prevented degradation of the active substance, showed triggered release properties in simulated intracellular reducing environments, and had higher structural stability and mucoadhesiveness when compared with nonmodified chitosan nanoparticles. ${ }^{148}$

\section{Presence of ligands on the surface}

The presence of ligands on the surface of nanoparticles also affects cellular uptake. For example, PEGylated nanoparticles with endocytic and nonendocytic receptors show the important role of receptor-mediated endocytosis in the efficacy of nanoparticles used in the imaging and treatment of cancer. ${ }^{35}$ Thus, doxorubicin-loaded nanoparticles with endocytic receptors showed better cellular uptake and anticancer efficiency than those with nonendocytic receptors.

Another interesting therapeutic target that can benefit from ligand-conjugated nanoparticles is the endothelial lining. In order to deliver to this site, a new class of nanocarriers called filomicelles has been conjugated with antibodies against specific endothelial surface epitopes. Antibody-conjugated filomicelles show that it is possible to formulate stable and dynamically flexible particles that successfully anchor onto their target despite the effect of blood flow. ${ }^{149}$

\section{Toxicity}

PLGA has shown minimal systemic toxicity and excellent biocompatibility in vitro and in vivo. However, some inflammatory responses have been reported..$^{39,150,151}$ PGA has low solubility and a high degradation rate, with formation of an acidic product that can also provoke an 
inflammatory reaction. ${ }^{14}$ For this reason, use of PGA in biomedical applications is limited, and other options like caprolactone, lactide, and trimethylene carbonate have been developed to eliminate these toxic products. ${ }^{152}$

Another concern is adducts of biopolymer production which remain after purification methods. For instance, polyurethanes may contain some remnants of toxic methylene diamine that are produced by inefficient mixing, limited polymerization, and insufficient post purification of the polymer. ${ }^{15}$ Further, the products of hydrolysis of biodegradable polymers (carboxylic acid and/or hydroxyl chain end) may be oxidized, producing species such as short chain carboxylic acid, that may lead to local variations in $\mathrm{pH}$ that trigger an inflammatory response. ${ }^{15,153}$

There are controversies related to the safety or toxicity of polymeric nanomaterials for biomedical application. For example, some authors report that chitosan only reduces the side effects of some drugs such as doxorubicin, but also improves therapeutic efficacy. ${ }^{154}$ However, other studies showed that membrane damage and leakage of alanine transaminase out of the hepatocyte were due to direct interaction with chitosan nanoparticles. ${ }^{155}$

On the other hand, polymers such as PEI are cytotoxic. ${ }^{156}$ It has been demonstrated that PEI causes destabilization of the plasma membrane and activation of effector caspase-3, so PEI appears to be an apoptotic agent. ${ }^{156}$ However, modifications in its structure may address this concern and make it suitable for medical application. ${ }^{157,158}$ Further, PEI confers resistance to enzymatic degradation, as shown by micellelike nanoparticles ${ }^{159}$ and Tween 85 -modified PEI particles ${ }^{160}$ where DNA was completely protected when loaded into these formulations.

Table 4 shows the results of in vitro toxicity studies for some of the most important biodegradable polymers used in medical applications. The majority of these results report minimal or nontoxic effects of polymer nanoparticles in themselves; however, a complete scan for possible effects of biopolymer-drug combinations at the nanosize level is required for each system.

In this review, we have focused on the toxicity of biopolymers. Other nanomaterials, such as metallic nanoparticles (gold, iron, titanium, or silica), carbon nanotubes, or fullerenes, are beyond the scope of this discussion.

\section{Polymers with FDA approval}

PLA, PLGA, and polycaprolactone are the most widely used biodegradable polymers because of their biocompatibility, biodegradability, and mechanical properties. Nevertheless, a complete list of biodegradable polymers approved by the FDA for biomedical application is shown in Table 5.

Table 4 In vitro toxicity studies of commonly used biodegradable polymers in medical applications

\begin{tabular}{|c|c|c|c|}
\hline Polymer & Assay & Results & Reference \\
\hline $\begin{array}{l}\text { PEG (positively and } \\
\text { negatively charged) }\end{array}$ & $\begin{array}{l}\text { - MTT cell proliferation assay in NR8383 } \\
\text { and Caco- } 2 \text { cells } \\
\text { - Mitochondrial membrane potential induction } \\
\text { of reactive oxygen species production } \\
\text { - ATP depletion and TNF- } \alpha \text { release }\end{array}$ & $\begin{array}{l}\text { - Positively charged nanoparticles of } 45 \mathrm{~nm} \\
\text { were more cytotoxic than } 90 \mathrm{~nm} \text { nanoparticles } \\
\text { - Negatively charged nanoparticles of both } \\
45 \mathrm{~nm} \text { and } 90 \mathrm{~nm} \text { did not induce significant } \\
\text { cytotoxic responses }\end{array}$ & 174 \\
\hline $\begin{array}{l}\text { Polyvinyl alcohol, PEG, } \\
\text { and polyvinyl chloride }\end{array}$ & - MTT test in MRC5 human lung fibroblasts & $\begin{array}{l}\text { - Polyvinyl chloride and PEG were not cytotoxic } \\
\text { - Polyvinyl alcohol did not inhibit cell proliferation } \\
\text { and did not lead to morphology changes }\end{array}$ & 175 \\
\hline $\begin{array}{l}\text { PLGA, poly( } \varepsilon \text {-carbobenzoxy- } \\
\text { L-lysine) }\end{array}$ & $\begin{array}{l}\text { - MTT assay in rat endothelial cells } \\
\text { and human umbilical vein } \\
\text { endothelial cells }\end{array}$ & $\begin{array}{l}\text { - No toxicity was seen in cells exposed to PLGA- } \\
\text { poly( } \varepsilon \text {-carbobenzoxy-L-lysine) or PLGA } \\
\text { at concentrations or time points assessed }\end{array}$ & 176 \\
\hline \multirow[t]{2}{*}{ Chitosan } & $\begin{array}{l}\text { - Zebrafish embryo model: embryos } \\
\text { were exposed to chitosan nanoparticles } \\
\text { for } 96 \text { hours, and dose-dependent } \\
\text { inhibition of embryo hatching was } \\
\text { determined }\end{array}$ & $\begin{array}{l}\text { - A significant decrease in hatching rate } \\
\text { was observed at } 20 \mathrm{mg} / \mathrm{L} \text { and } 40 \mathrm{mg} / \mathrm{L} \\
\text { concentrations of } 340 \mathrm{~nm} \text { chitosan nanoparticles } \\
\text { - A significant decrease in hatching rate } \\
\text { was observed at } 30 \mathrm{mg} / \mathrm{L} \text { and } 40 \mathrm{mg} / \mathrm{L} \\
\text { of } 200 \mathrm{~nm} \text { chitosan nanoparticles } \\
\text { - At higher concentrations, chitosan nanoparticles } \\
\text { were toxic to the zebrafish embryos }\end{array}$ & 177 \\
\hline & - MTT assay in Caco-2 cell toxicity & $\begin{array}{l}\text { - Fucoidan-chitosan, in non-nanoparticle form, } \\
\text { decreased cell viability of Caco- } 2 \text { cells } \\
\text { - Fucoidan-chitosan nanoparticles }(250,500 \text {, } \\
\text { and } 1,000 \mu \mathrm{g} / \mathrm{mL}) \text { were not cytotoxic }\end{array}$ & 178 \\
\hline
\end{tabular}

Abbreviations: PEG, poly(ethylene glycol); MTT, 3-(4,5-dimethylthiazol-2-yl)-2,5-diphenyltetrazolium bromide; ATP, adenosine triphosphate; TNF- $\alpha$, tumor necrosis factor-alpha; PLGA, poly(lactic-co-glycolic acid); MRC5, human fetal lung fibroblast cells; Caco-2, human colon carcinoma cells. 
Table 5 List of biodegradable polymers approved by the US Food and Drug Administration for use in the preparation of nanodrugs updated to September 2012 (http://www.accessdata.fda.gov/scripts/cder/iig/index.cfm)

\begin{tabular}{|c|c|c|}
\hline Polymer & Route, dosage form & CAS numbe \\
\hline Acrylates copolymer & TD, controlled-release patch & _ \\
\hline Acrylic acid-isooctyl acrylate copolymer & TD, controlled-release film & - \\
\hline Ammonio methacrylate copolymer & O, tablet & - \\
\hline Ammonio methacrylate copolymer type $A$ & O, extended-release capsule & 33434241 \\
\hline Ammonio methacrylate copolymer type B & O, extended-release tablet & 33434241 \\
\hline $\begin{array}{l}\text { Butyl ester of vinyl methyl ether/maleic anhydride copolymer } \\
\text { (I 25,000 molecular weight) }\end{array}$ & $\mathrm{T}$, solution & 25119680 \\
\hline Carbomer homopolymer type A (allyl pentaerythritol crosslinked) & O, extended-release tablet & | 38757683 \\
\hline Carbomer homopolymer type B (allyl sucrose crosslinked) & $\mathrm{T}$, gel & - \\
\hline Carboxy vinyl copolymer & $\mathrm{T}$, gel & - \\
\hline Cellulosic polymers & O, capsule, enteric-coated pellets & - \\
\hline $\begin{array}{l}\text { Dimethylaminoethyl methacrylate-butyl methacrylate-methyl } \\
\text { methacrylate copolymer }\end{array}$ & O, sustained-action capsule & - \\
\hline Dimethylsiloxane/methylvinylsiloxane copolymer & I, pellet, implant & _ \\
\hline Divinylbenzene styrene copolymer & $\mathrm{OPH}$, suspension, drops & - \\
\hline Ethyl acrylate-methacrylic acid copolymer & O, delayed-action, coated, hard gelatin capsule & - \\
\hline $\begin{array}{l}\text { Ethyl acrylate and methyl methacrylate copolymer } \\
\text { (2:1; } 750,000 \text { molecular weight) }\end{array}$ & O, capsule, enteric-coated pellets & - \\
\hline Ethylene vinyl acetate copolymer & I, rod & - \\
\hline Ethylene-propylene copolymer & TD, controlled-release film & - \\
\hline Ethylene-vinyl acetate copolymer ( $28 \%$ vinyl acetate) & $\mathrm{V}$, insert & - \\
\hline Glycerin polymer solution i- 137 & O, tablet & - \\
\hline Glycerin polymer solution im- I 37 & O, tablet & - \\
\hline Hydrogel polymer & $\mathrm{V}$, extended-release insert & - \\
\hline $\begin{array}{l}\text { Ink/polyethylene terephthalate/aluminum/polyethylene/sodium } \\
\text { polymethacrylate/ethylene vinyl acetate copolymer }\end{array}$ & TD, controlled-release film & - \\
\hline $\begin{array}{l}\text { Isooctyl acrylate/acrylamide/vinyl acetate copolymer, } \\
\text { Kollidon }{ }^{\circledast} \text { VA } 64 \text { polymer }\end{array}$ & O, tablet, film-coated & - \\
\hline Methacrylic acid-ethyl acrylate copolymer $(I: I)$ type A & O, capsule & 25212888 \\
\hline Methacrylic acid-methyl methacrylate copolymer (I:I) & O, capsule & $25086|5|$ \\
\hline Methacrylic acid-methyl methacrylate copolymer (I:2) & O, tablet & $25086|5|$ \\
\hline Methacrylic acid copolymer & O, capsule & - \\
\hline Methacrylic acid copolymer type A & O, sustained-action, coated tablet & $\overline{2} 5086|5|$ \\
\hline Methacrylic acid copolymer type B & O, extended-release capsule & 25086151 \\
\hline Methacrylic acid copolymer type $C$ & O, sustained-action tablet & 25212888 \\
\hline Octadecene- $1 /$ maleic acid copolymer & $\mathrm{T}$, lotion & - \\
\hline PEG-22 methyl ether/dodecyl glycol copolymer & $\mathrm{T}$, cream, augmented & - \\
\hline PEG-45/dodecyl glycol copolymer & $\mathrm{T}$, cream, augmented & - \\
\hline Polyester polyamine copolymer & TD, controlled-release film & - \\
\hline Poly(ethylene glycol) I,000 & $\begin{array}{l}\mathrm{O}, \mathrm{R}, \mathrm{RP} \text {, and } \mathrm{V} \text {; concentrate, solution, tablet, film-coated, } \\
\text { suppository, aerosol, metered, emulsion, aerosol foam }\end{array}$ & 25322683 \\
\hline Poly(ethylene glycol) I,450 & $\begin{array}{l}\mathrm{O}, \mathrm{T} \text {, and } \mathrm{U} \text {; solution, suspension, extended-release tablet, } \\
\text { film-coated, topical, ointment, suppository }\end{array}$ & 25322683 \\
\hline Poly(ethylene glycol) I,500 & $\mathrm{O}$ and $\mathrm{T}$; tablet, ointment & 25322683 \\
\hline Poly(ethylene glycol) I,540 & D and R; gel, paste, solution, tablet, coated, ointment & 25322683 \\
\hline Poly(ethylene glycol) 200 & $\begin{array}{l}\text { IM, O, and } \mathrm{T} \text {; injection, capsule, solution, tablet } \\
\text { extended-release, ointment }\end{array}$ & 112607 \\
\hline Poly(ethylene glycol) 20,000 & O, hard gelatin capsule, delayed-action, enteric-coated tablet & 25322683 \\
\hline Poly(ethylene glycol) 200,000 & $\mathrm{O}$, extended-release tablet & - \\
\hline Poly(ethylene glycol) $2,000,000$ & O, tablet & - \\
\hline Poly(ethylene glycol) 300 & IV, IM, OPH, and T; injection, film-coated tablet & 2615158 \\
\hline Poly(ethylene glycol) 300-I,600 & O, tablet, delayed-action, enteric-coated & - \\
\hline Poly(ethylene glycol) 300-I,600 & $\mathrm{T}$, ointment & - \\
\hline Poly(ethylene glycol) 3,350 & $\begin{array}{l}\text { IA, IL, IM, N, SC, and T; injection, solution, spray, } \\
\text { soft gelatin capsule, extended-release tablet, ointment }\end{array}$ & 25322683 \\
\hline
\end{tabular}


Table 5 (Continued)

\begin{tabular}{|c|c|c|}
\hline Polymer & Route, dosage form & CAS number \\
\hline Poly(ethylene glycol) 3,500 & O, suspension, sustained-action tablet, film-coated tablet & 25322683 \\
\hline Poly(ethylene glycol) 400 & $\begin{array}{l}\text { IV, N, OPH, O, R, T, and V; injection, spray metered, } \\
\text { ointment, capsule, capsule coated soft gelatin, capsule soft gelatin } \\
\text { liquid-filled, capsule extended-release, capsule sustained-action } \\
\text { hard gelatin, oral syrup, controlled-release tablet, enteric-coated } \\
\text { particles tablet, suppository, emulsion cream }\end{array}$ & 25322683 \\
\hline Poly(ethylene glycol) 4,000 & $\begin{array}{l}\text { IA, IL, IM, O, R, SL, and V; injection, capsule, capsule } \\
\text { enteric-coated pellets, delayed-action enteric-coated tablet, } \\
\text { extended-release tablet, sustained-action tablet, suppository, } \\
\text { sublingual tablet, emulsion cream }\end{array}$ & 25322683 \\
\hline Poly(ethylene glycol) 4,500 & O, tablet-coated, tablet film-coated & 25322683 \\
\hline Poly(ethylene glycol) 540 & $\mathrm{~T}$, ointment & 25322683 \\
\hline Poly(ethylene glycol) 600 & $\begin{array}{l}\text { IV, O, and } \mathrm{T} \text {; injection, soft gelatin capsule, soft gelatin } \\
\text { liquid-filled capsule, tablet, delayed-action enteric-coated tablet, } \\
\text { solution, sustained-action tablet }\end{array}$ & 25322683 \\
\hline Poly(ethylene glycol) 6,000 & $\begin{array}{l}\mathrm{O}, \mathrm{R}, \mathrm{T} \text {, and } \mathrm{V} \text {; capsules, extended-release capsule, } \\
\text { hard gelatin capsule, sustained-action capsule, (immed/comp } \\
\text { release) film-coated tablet, delayed-action tablet, delayed-action } \\
\text { enteric-coated tablet, sustained-action coated tablet, } \\
\text { suppository, emulsion cream, film-coated tablet }\end{array}$ & 25322683 \\
\hline Poly(ethylene glycol) 7,000 & O, controlled-release tablet, extended-release tablet & 25322683 \\
\hline Poly(ethylene glycol) $7,000,000$ & O, tablet, extended-release & - \\
\hline Poly(ethylene glycol) 800 & O, tablet & 25322683 \\
\hline Poly(ethylene glycol) 8,000 & $\begin{array}{l}\mathrm{O}, \mathrm{OPH}, \mathrm{T} \text {, and } \mathrm{V} \text {; solution, hard gelatin capsule, } \\
\text { sustained-action capsule, (immed/comp release) uncoated } \\
\text { chewable tablet, delayed-action enteric-coated tablet, orally } \\
\text { disintegrating delayed-release tablet, sustained-action } \\
\text { coated tablet, emulsion cream, topical powder, vaginal tablet }\end{array}$ & 25322683 \\
\hline Poly(ethylene glycol) 900 & $\mathrm{~T}$, ointment, solution & 25322683 \\
\hline Polyvinyl chloride-polyvinyl acetate copolymer & TD, controlled-release film & - \\
\hline Povidone acrylate copolymer & $\mathrm{T}$, liquid solution & - \\
\hline Povidone/eicosene copolymer & $\mathrm{T}$, lotion & 28211189 \\
\hline $\begin{array}{l}\text { Polyoxy(methyl-I,2-ethanediyl), alpha-hydro-omega-hydroxy-, } \\
\text { polymer with I,I'-methylenebis[4-isocyanatocyclohexane] } \\
\text { copolymer (Ppg-I2/SMDI) }\end{array}$ & $\mathrm{T}$, lotion & 9042824 \\
\hline Polyvinyl methyl ether/maleic acid copolymer (PVM/MA) & $\mathrm{D}$, paste & 9011169 \\
\hline Styrene/isoprene/styrene block copolymer & $\mathrm{T}$, patch & - \\
\hline Vinyl acetate-crotonic acid copolymer & O, sustained-action capsule & - \\
\hline
\end{tabular}

Abbreviations: D, dental; I, implantation; IA, intra-articular; IL, intralesional; IM, intramuscular; IV, intravenous; N, nasal; O, oral; OPH, ophthalmic; R, rectal; RP, respiratory; SC, subcutaneous; SL, sublingual; TD, transdermal; T, topical; U, urethral; V, vaginal; MTT, 3-(4,5-dimethylthiazol-2-yl)-2,5-diphenyltetrazolium bromide; ATP, adenosine triphosphate; TNF- $\alpha$, tumor necrosis factor-alpha; PEG, poly(ethylene glycol); CAS, chemical abstracts service; immed/comp release, immediate release solid dosage form.

\section{Conclusion}

There have been many advances in the production of more stable, efficient, and safe nanocarriers, and formulations and manufacturing processes will undoubtedly continue to evolve. The treatment of major diseases with worldwide economic importance has been proven to benefit from these nanosystems, although there are still few nanodrugs available on the pharmaceutical market.

Many methods for synthesis and modification of biodegradable polymers have been established, but it is still relevant to develop new technologies to allow use of minimally toxic reagents, protect the active compounds, and scale up to an industrial level.
Goals like increasing the degradation rate of polymeric matrices, reducing undesirable side effects, and improving the efficiency of drugs have been partially achieved by development of polymeric matrices which can be degraded in specific conditions and reach specific receptors that improve their cellular uptake.

\section{Acknowledgments}

Thanks are due to the National Secretariat for Science, Technology, and Innovation of Panama for financial support (grant Fie10-08) and to The Institute for Training and Development of Human Resources (IFARHU) from the Panamanian government which, jointly with the National Secretariat for 
Science, Technology, and Innovation, provided EM with a scholarship. We are grateful to Jagannatha Rao, Marisín Pecchio, Dominique Gutierrez, and Suyin Torres for critically reviewing this work. The authors wish to dedicate this work to the memory of Dr Gustavo Nuñez, whose leadership and creative ideas inspired this work.

\section{Disclosure}

The authors report no conflicts of interest in this work.

\section{References}

1. Liechty WB, Peppas NA. Expert opinion: responsive polymer nanoparticles in cancer therapy. Eur J Pharm Biopharm. 2012;80:241-246.

2. Ryvolova M, Chomoucka J, Drbohlavova J, et al. Modern micro and nanoparticle-based imaging techniques. Sensors (Basel). 2012;12: 14792-14820.

3. Ulery BD, Nair LS, Laurencin CT. Biomedical applications of biodegradable polymers. J Polym Sci B Polym Phys. 2011;49:832-864.

4. Vroman I, Tighzert L. Biodegradable polymers. Materials. 2009;2: 307-344.

5. Nitta SK, Numata K. Biopolymer-based nanoparticles for drug/gene delivery and tissue engineering. Int J Mol Sci. 2013;14:1629-1654.

6. Nair LS, Laurencin CT. Polymers as biomaterials for tissue engineering and controlled drug delivery. Adv Biochem Eng Biotechnol. 2006;102:47-90.

7. Park JH, Ye M, Park K. Biodegradable polymers for microencapsulation of drugs. Molecules. 2005;10:146-161.

8. Mohanraj V, Chen Y. Nanoparticles: a review. Trop J Pharm Res. 2006;5:561-573.

9. Elzoghby AO, Samy WM, Elgindy NA. Albumin-based nanoparticles as potential controlled release drug delivery systems. $J$ Control Release. 2012;157:168-182.

10. Malhotra M, Lane C, Tomaro-Duchesneau C, Saha S, Prakash S. A novel method for synthesizing PEGylated chitosan nanoparticles: strategy, preparation, and in vitro analysis. Int J Nanomedicine. 2011;6:485-494.

11. Bhattacharyya SS, Paul S, Khuda-Bukhsh AR. Encapsulated plant extract (Gelsemium sempervirens) poly (lactide-co-glycolide) nanoparticles enhance cellular uptake and increase bioactivity in vitro. Exp Biol Med (Maywood). 2010;235:678-688.

12. Grenha A, Grainger CI, Dailey LA, et al. Chitosan nanoparticles are compatible with respiratory epithelial cells in vitro. Eur J Pharm Sci. 2007;31:73-84.

13. Liu H, Slamovich EB, Webster TJ. Less harmful acidic degradation of poly(lacticco-glycolic acid) bone tissue engineering scaffolds through titania nanoparticle addition. Int J Nanomedicine. 2006;1:541-545.

14. Ceonzo K, Gaynor A, Shaffer L, Kojima K, Vacanti CA, Stahl GL. Polyglycolic acid-induced inflammation: role of hydrolysis and resulting complement activation. Tissue Eng. 2006;12:301-308.

15. Lyu S, Untereker D. Degradability of polymers for implantable biomedical devices. Int J Mol Sci. 2009;10:4033-4065.

16. Jain A, Gupta Y, Jain SK. Perspectives of biodegradable natural polysaccharides for site-specific drug delivery to the colon. J Pharm Pharm Sci. 2007;10:86-128.

17. Modi G, Pillay V, Choonara YE. Advances in the treatment of neurodegenerative disorders employing nanotechnology. Ann N Y Acad Sci. 2010;1184:154-172.

18. Patel DN, Bailey SR. Nanotechnology in cardiovascular medicine. Catheter Cardiovasc Interv. 2007;69:643-654.

19. Hu D, Liu L, Chen W, Li S, Zhao Y. A novel preparation method for 5-aminosalicylic acid loaded Eudragit s100 nanoparticles. Int $J$ Mol Sci. 2012;13:6454-6468.

20. Soppimath KS, Aminabhavi TM, Kulkarni AR, Rudzinski WE. Biodegradable polymeric nanoparticles as drug delivery devices. J Control Release. 2001;70:1-20.
21. Bawa R. NanoBiotech 2008: exploring global advances in nanomedicine. Nanomedicine. 2009;5:5-7.

22. Tangpasuthadol V, Pendharkar SM, Kohn J. Hydrolytic degradation of tyrosine-derived polycarbonates, a class of new biomaterials. Part I: study of model compounds. Biomaterials. 2000;21:2371-2378.

23. Jeong SI, Kim BS, Kang SW, et al. In vivo biocompatibilty and degradation behavior of elastic poly(L-lactide-co-epsilon-caprolactone) scaffolds. Biomaterials. 2004;25:5939-5946.

24. Rawat M, Singh D, Saraf S. Nanocarriers: promising vehicle for bioactive drugs. Biol Pharm Bull. 2006;29:1790-1798.

25. Kulkarni RK, Pani KC, Neuman C, Leonard F. Polylactic acid for surgical implants. Arch Surg. 1966;93:839-843.

26. Yan H, Jiang W, Zhang Y, et al. Novel multi-biotin grafted poly(lactic acid) and its self-assembling nanoparticles capable of binding to streptavidin. Int J Nanomedicine. 2012;7:457-465.

27. Godin B, Sakamoto JH, Serda RE, Grattoni A, Bouamrani A, Ferrari M. Emerging applications of nanomedicine for the diagnosis and treatment of cardiovascular diseases. Trends Pharmacol Sci. 2010;31:199-205.

28. Lee $\mathrm{CH}$. Characterization of nitric oxide delivery systems produced by various nanotechnologies. Methods Mol Biol. 2011;704:169-185.

29. Saraiva J, Marotta-Oliveira SS, Cicillini SA, Eloy Jde O, Marchetti JM Nanocarriers for nitric oxide delivery. J Drug Deliv. 2011;2011: 936438.

30. El-Sherbiny IM, Smyth HD. Controlled release pulmonary administration of curcumin using swellable biocompatible microparticles. Mol Pharm. 2012;9:269-280.

31. Zhang XD, Wu D, Shen X, et al. Size-dependent in vivo toxicity of PEGcoated gold nanoparticles. Int J Nanomedicine. 2011;6:2071-2081.

32. Xu X, Yu H, Gao S, Ma HQ, Leong KW, Wang S. Polyphosphoester microspheres for sustained release of biologically active nerve growth factor. Biomaterials. 2002;23:3765-3772.

33. Shenoy D, Little S, Langer R, Amiji M. Poly(ethylene oxide)-modified poly(beta-amino ester) nanoparticles as a $\mathrm{pH}$-sensitive system for tumor-targeted delivery of hydrophobic drugs. 1. In vitro evaluations. Mol Pharm. 2005;2:357-366.

34. Cheng L, Jin C, Lv W, Ding Q, Han X. Developing a highly stable PLGA-mPEG nanoparticle loaded with cisplatin for chemotherapy of ovarian cancer. PLoS One. 2011;6:e25433.

35. Chuang KH, Wang HE, Chen FM, et al. Endocytosis of PEGylated agents enhances cancer imaging and anticancer efficacy. Mol Cancer Ther. 2010;9:1903-1912.

36. Mo X, Iwata H, Matsuda S, Ikada Y. Soft tissue adhesive composed of modified gelatin and polysaccharides. J Biomater Sci Polym Ed. 2000;11:341-351.

37. Ikada Y, Tsuji H. Biodegradable polyesters for medical and ecological applications. Macromol Rapid Commun. 2000;21:117-132.

38. Hino M, Ishiko O, Honda KI, et al. Transmission of symptomatic parvovirus B19 infection by fibrin sealant used during surgery. $\mathrm{Br} \mathrm{J}$ Haematol. 2000;108:194-195.

39. Lu JM, Wang X, Marin-Muller C, et al. Current advances in research and clinical applications of PLGA-based nanotechnology. Expert Rev Mol Diagn. 2009;9:325-341.

40. Sachlos E, Czernuszka JT. Making tissue engineering scaffolds work. Review: the application of solid freeform fabrication technology to the production of tissue engineering scaffolds. Eur Cell Mater. 2003;5:29-39.

41. Feng Y, Guo J. Biodegradable polydepsipeptides. Int J Mol Sci. 2009;10:589-615.

42. Garaleh M. Synthesis of poly(ether-ester) catalyzed by bismuth triflate. Eur J Sci Res. 2011;55:383-387.

43. Rodriguez-Galan A, Franco L, Puiggali J. Degradable poly(ester amide)s for biomedical applications. Polymers. 2011;3:69-99.

44. Stridsberg KM, Ryner M, Albertsson AC. Controlled ring-opening polymerization: polymers with designed macromolecular architecture. Degradable Aliphatic Polyesters. Berlin, Germany: Springer; 2002.

45. Merlin DL, Sivasankar B. Synthesis and characterization of semiinterpenetrating polymer networks using biocompatible polyurethane and acrylamide monomer. Eur Polym J. 2009;45:165-170. 
46. Macocinschi D, Filip D, Vlad S, Oprea AM, Gafitanu CA. Characterization of a poly(ether urethane)-based controlled release membrane system for delivery of ketoprofen. Appl Surf Sci. 2012;259:416-423.

47. Leong KW, Simonte V, Langer R. Synthesis of polyanhydrides: meltpolycondensation, dehydrochlorination, and dehydrative coupling. Macromolecules. 1987;20:705-712.

48. Sintzel MB, Heller J, Ng SY, Tabatabay C, Schwach-Abdellaoui K, Gurny R. In vitro drug release from self-catalyzed poly(ortho ester): case study of 5-fluorouracil. J Control Release. 1998;55:213-218.

49. Azevedo HS, Reis RL. Understanding the enzymatic degradation of biodegradable polymers and strategies to control their degradation rate. In: Rui L, Reis JSR, editors. Biodegradable Systems in Tissue Engineering and Regenerative Medicine. Boca Ratio, FL: CRC Press; 2004.

50. Edlund U, Albertsson AC. Degradable polymer microspheres for controlled drug delivery. In: Albertsson AA, Dusek AC, editors. Advances in Polymer Science. Berlin, Germany: Springer-Verlag; 2002.

51. Uhrich KE, Cannizzaro SM, Langer RS, Shakesheff KM. Polymeric systems for controlled drug release. Chem Rev. 1999;99:3181-3198.

52. Hurrell S, Cameron RE. Polyglycolide: degradation and drug release. Part I: changes in morphology during degradation. J Mater Sci Mater Med. 2001;12:811-816.

53. Ward R, Anderson J, McVenes R, Stokes K. In vivo biostability of polysiloxane polyether polyurethanes: resistance to biologic oxidation and stress cracking. J Biomed Mater Res A. 2006;77:580-589.

54. Napoli A, Valentini M, Tirelli N, Muller M, Hubbell JA. Oxidationresponsive polymeric vesicles. Nat Mater. 2004;3:183-189.

55. Chen L, Li X, Li L, Guo S. Acetylated starch-based biodegradable materials with potential biomedical applications as drug delivery systems. Curr Appl Phys. 2007;7:e90-e93.

56. Wu Y, Yang W, Wang C, Hu J, Fu S. Chitosan nanoparticles as a novel delivery system for ammonium glycyrrhizinate. Int J Pharm. 2005;295:235-245.

57. Sarmento B, Ribeiro A, Veiga F, Sampaio P, Neufeld R, Ferreira D. Alginate/chitosan nanoparticles are effective for oral insulin delivery. Pharm Res. 2007;24:2198-2206.

58. Trickler WJ, Nagvekar AA, Dash AK. A novel nanoparticle formulation for sustained paclitaxel delivery. AAPSPharmSciTech. 2008;9:486-493.

59. Cheng J, Teply BA, Sherifi I, et al. Formulation of functionalized PLGAPEG nanoparticles for in vivo targeted drug delivery. Biomaterials. 2007;28:869-876.

60. Du YZ, Cai LL, Li J, et al. Receptor-mediated gene delivery by folic acidmodified stearic acid-grafted chitosan micelles. Int J Nanomedicine. 2011;6:1559-1568.

61. Fanga Z, Bhandaria B. Encapsulation of polyphenols - a review. Trends Food Sci Technol. 2010;21:510-523.

62. Pinto Reis C, Neufeld RJ, Ribeiro AJ, Veiga F. Nanoencapsulation I. Methods for preparation of drug-loaded polymeric nanoparticles. Nanomedicine. 2006;2:8-21.

63. Duan J, Zhang Y, Chen W, et al. Cationic polybutyl cyanoacrylate nanoparticles for DNA delivery. J Biomed Biotechnol. 2009;2009: 149254.

64. Yang SC, Ge HX, Hu Y, Jiang XQ, Yang CZ. Formation of positively charged poly(butyl cyanoacrylate) nanoparticles stabilized with chitosan. Colloid Polym Sci. 2000;278:285-292.

65. Miyazaki S, Takahashi A, Kubo W, Bachynsky J, Loebenberg R. Poly n-butylcyanoacrylate (PNBCA) nanocapsules as a carrier for NSAIDs: in vitro release and in vivo skin penetration. J Pharm Pharm Sci. 2003;6:238-245.

66. Essawy H, Tauer K. Polyamide capsules via soft templating with oil drops-1. Morphological studies of the capsule wall. Colloid Polym Sci. 2010;288:317-331.

67. Crespy D, Landfester K. Miniemulsion polymerization as a versatile tool for the synthesis of functionalized polymers. Beilstein J Org Chem. 2010;6:1132-1148.

68. Hans ML, Lowman AM. Biodegradable nanoparticles for drug delivery and targeting. Curr Opin Solid State Mater Sci. 2002;6:319-327.
69. Hong Y, Gao C, Shi Y, Shen J. Preparation of porous polylactide microspheres by emulsion-solvent evaporation based on solution induced phase separation. Polym Adv Technol. 2005;16:622-627.

70. Nagpal K, Kumar Singh SK, Mishra DN. Chitosan nanoparticles: a promising system in novel drug delivery. Chem Pharm Bull (Tokyo). 2010;58:1423-1430.

71. Yun Y, Cho YW, Park K. Nanoparticles for oral delivery: targeted nanoparticles with peptidic ligands for oral protein delivery. Adv Drug Deliv Rev. 2013;65:822-832.

72. Galindo-Rodriguez S, Allemann E, Fessi H, Doelker E. Physicochemical parameters associated with nanoparticle formation in the salting-out, emulsification-diffusion, and nanoprecipitation methods. Pharm Res. 2004;21:1428-1439.

73. Troy DB, editor. Remington: The Science and Practice of Pharmacy. 21st ed. Philadelphia, PA: Lippincott Williams \& Wilkin; 2006.

74. Murakami H, Kobayashi M, Takeuchi H, Kawashima Y. Preparation of poly(DL-lactide-co-glycolide) nanoparticles by modified spontaneous emulsification solvent diffusion method. Int J Pharm. 1999;187: 143-152.

75. Makadia HK, Siegel SJ. Poly lactic-co-glycolic acid (PLGA) as biodegradable controlled drug delivery carrier. Polymers (Basel). 2011;3:1377-1397.

76. Cansell F, Aymonier C. Design of functional nanostructured materials using supercritical fluids. J Supercrit Fluids. 2009;47:508-516.

77. Gupta VK, Karar PK, Ramesh S, Misra SP, Gupta A. Nanoparticle formulation for hydrophilic and hydrophobic drugs. Int J Res Pharm Sci. 2010;1:163-169.

78. Reverchon E, Adami R. Nanomaterials and supercritical fluids. J Supercrit Fluids. 2006;37:1-22.

79. Irfan M, Seiler M. Encapsulation using hyperbranched polymers: from research and technologies to emerging applications. Ind Eng Chem Res. 2010;49:1169-1196.

80. Gomez S, Gamazo C, San Roman B, Vauthier C, Ferrer M, Irachel JM. Development of a novel vaccine delivery system based on Gantrez nanoparticles. J Nanosci Nanotechnol. 2006;6:3283-3289.

81. Kowalczyk B, Lagzi I, Grzybowski BA. Nanoseparations: strategies for size and/or shape-selective purification of nanoparticles. Curr Opin Colloid Interface Sci. 2011;16:135-148.

82. Abdelwahed W, Degobert G, Stainmesse S, Fessi H. Freeze-drying of nanoparticles: formulation, process and storage considerations. $A d v$ Drug Deliv Rev. 2006;58:1688-1713.

83. Biro E, Nemeth AS, Sisak C, Feczko T, Gyenis J. Preparation of chitosan particles suitable for enzyme immobilization. J Biochem Biophys Methods. 2008;70:1240-1246.

84. Lemoine D, Francois C, Kedzierewicz F, Preat V, Hoffman M, Maincent P. Stability study of nanoparticles of poly(epsiloncaprolactone), poly(D,L-lactide) and poly(D,L-lactide-co-glycolide). Biomaterials. 1996;17:2191-2197.

85. Mima Y, Fukumoto S, Koyama H, et al. Enhancement of cell-based therapeutic angiogenesis using a novel type of injectable scaffolds of hydroxyapatite-polymer nanocomposite microspheres. PLoS One. 2012; 7:e35199.

86. Venkatesan J, Kim SK. Chitosan composites for bone tissue engineering - an overview. Mar Drugs. 2010;8:2252-2266.

87. Jagur-Grodzinski J. Biomedical application of functional polymers. React Funct Polym. 1999;39:99-138.

88. Wilczewska AZ, Niemirowicz K, Markiewicz KH, Car H. Nanoparticles as drug delivery systems. Pharmacol Rep. 2012;64:1020-1037.

89. Vilar G, Tulla-Puche J, Albericio F. Polymers and drug delivery systems. Curr Drug Deliv. 2012;9:367-394.

90. Mei L, Zhang Y, Zheng Y, et al. A novel docetaxel-loaded poly (epsiloncaprolactone)/Pluronic F68 nanoparticle overcoming multidrug resistance for breast cancer treatment. Nanoscale Res Lett. 2009;4:1530-1539.

91. Mitra M, Misra R, Harilal A, Sahoo SK, Krishnakumar S. Enhanced in vitro antiproliferative effects of EpCAM antibody-functionalized paclitaxel-loaded PLGA nanoparticles in retinoblastoma cells. Mol Vis. 2011;17:2724-2737. 
92. Foged C, Nielsen HM. Cell-penetrating peptides for drug delivery across membrane barriers. Expert Opin Drug Deliv. 2008;5:105-117.

93. Ringman JM, Frautschy SA, Cole GM, Masterman DL, Cummings JL. A potential role of the curry spice curcumin in Alzheimer's disease Curr Alzheimer Res. 2005;2:131-136.

94. Mathew A, Fukuda T, Nagaoka Y, et al. Curcumin loaded-PLGA nanoparticles conjugated with Tet-1 peptide for potential use in Alzheimer's disease. PLoS One. 2012;7:e32616.

95. Songjiang Z, Lixiang W. Amyloid-beta associated with chitosan nanocarrier has favorable immunogenicity and permeates the BBB. AAPS PharmSciTech. 2009;10:900-905.

96. Azeem A, Talegaonkar S, Negi LM, Ahmad FJ, Khar RK, Iqbal Z. Oil based nanocarrier system for transdermal delivery of ropinirole: a mechanistic, pharmacokinetic and biochemical investigation. Int $J$ Pharm. 2012;422:436-444.

97. Malvindi MA, Di Corato R, Curcio A, et al. Multiple functionalization of fluorescent nanoparticles for specific biolabeling and drug delivery of dopamine. Nanoscale. 2011;3:5110-5119.

98. Di Stefano A, Iannitelli A, Laserra S, Sozio P. Drug delivery strategies for Alzheimer's disease treatment. Expert Opin Drug Deliv. 2011;8 581-603.

99. Wickline SA, Neubauer AM, Winter P, Caruthers S, Lanza G. Applications of nanotechnology to atherosclerosis, thrombosis, and vascular biology. Arterioscler Thromb Vasc Biol. 2006;26:435-441.

100. Mutsuga M, Narita Y, Yamawaki A, et al. Development of novel drug-eluting biodegradable nano-fiber for prevention of postoperative pulmonary venous obstruction. Interact Cardiovasc Thorac Surg. 2009;8:402-407.

101. Cho HH, Han DW, Matsumura K, Tsutsumi S, Hyon SH. The behavior of vascular smooth muscle cells and platelets onto epigallocatechin gallate-releasing poly(l-lactide-co-epsilon-caprolactone) as stentcoating materials. Biomaterials. 2008;29:884-893.

102. Bharali DJ, Mousa SA, Thanavala Y. Micro- and nanoparticle-based vaccines for hepatitis B. Adv Exp Med Biol. 2007;601:415-421.

103. Demento S, Steenblock ER, Fahmy TM. Biomimetic approaches to modulating the $\mathrm{T}$ cell immune response with nano- and micro-particles. Conf Proc IEEE Eng Med Biol Soc. 2009;2009: 1161-1166.

104. Vinogradov SV, Poluektova LY, Makarov E, Gerson T, Senanayake MT. Nano-NRTIs: efficient inhibitors of HIV type-1 in macrophages with a reduced mitochondrial toxicity. Antivir Chem Chemother. 2010;21:1-14.

105. Dwivedi V, Manickam C, Binjawadagi B, Joyappa D, Renukaradhya GJ Biodegradable nanoparticle-entrapped vaccine induces cross-protective immune response against a virulent heterologous respiratory viral infection in pigs. PLoS One. 2012;7:e51794.

106. Brunel F, Veron L, David L, Domard A, Verrier B, Delair T. Self-assemblies on chitosan nanohydrogels. Macromol Biosci. 2010;10:424-432.

107. Liu H, Webster TJ. Ceramic/polymer nanocomposites with tunable drug delivery capability at specific disease sites. J Biomed Mater Res A. 2010;93:1180-1192.

108. Fox K, Tran PA, Tran N. Recent advances in research applications of nanophase hydroxyapatite. Chemphyschem. 2012;13:2495-2506.

109. Marrache S, Dhar S. Engineering of blended nanoparticle platform for delivery of mitochondria-acting therapeutics. Proc Natl Acad Sci U S A. 2012;109:16288-16293.

110. Sun D, Zhuang X, Xiang X, et al. A novel nanoparticle drug delivery system: the anti-inflammatory activity of curcumin is enhanced when encapsulated in exosomes. Mol Ther. 2010;18:1606-1614.

111. Anand P, Nair HB, Sung B, et al. Design of curcumin-loaded PLGA nanoparticles formulation with enhanced cellular uptake, and increased bioactivity in vitro and superior bioavailability in vivo. Biochem Pharmacol. 2010;79:330-338.

112. El-Shabouri MH. Positively charged nanoparticles for improving the oral bioavailability of cyclosporin-A. Int J Pharm. 2002;249: 101-108.
113. Banerjee SS, Aher N, Patil R, Khandare J. Poly(ethylene glycol)prodrug conjugates: concept, design, and applications. J Drug Deliv. 2012;2012:103973

114. Gref R, Domb A, Quellec P, et al. The controlled intravenous delivery of drugs using PEG-coated sterically stabilized nanospheres. Adv Drug Deliv Rev. 2012;16:215-233.

115. Zohuriaan-Mehr MJ. Advances in chitin and chitosan modification through graft copolymerization: a comprehensive review. Iran Polym J. 2005;14:235-265.

116. van Vlerken LE, Vyas TK, Amiji MM. Poly(ethylene glycol)-modified nanocarriers for tumor-targeted and intracellular delivery. Pharm Res. 2007;24:1405-1414.

117. Doherty GJ, McMahon HT. Mechanisms of endocytosis. Annu Rev Biochem. 2009;78:857-902.

118. Aderem A, Underhill DM. Mechanisms of phagocytosis in macrophages. Anпи Rev Immunol. 1999;17:593-623.

119. Groves E, Dart AE, Covarelli V, Caron E. Molecular mechanisms of phagocytic uptake in mammalian cells. Cell Mol Life Sci. 2008;65: 1957-1976.

120. Gratton SE, Ropp PA, Pohlhaus PD, et al. The effect of particle design on cellular internalization pathways. Proc Natl Acad Sci U SA. 2008;105:11613-11618.

121. Rejman J, Oberle V,Zuhorn IS, Hoekstra D. Size-dependent internalization of particles via the pathways of clathrin- and caveolae-mediated endocytosis. Biochem J. 2004;377:159-169.

122. Gandapu U, Chaitanya RK, Kishore G, Reddy RC, Kondapi AK. Curcumin-loaded apotransferrin nanoparticles provide efficient cellular uptake and effectively inhibit HIV-1 replication in vitro. PLoS One. 2011;6:e23388.

123. Ramanan V, Agrawal NJ, Liu J, Engles S, Toy R, Radhakrishnan R. Systems biology and physical biology of clathrin-mediated endocytosis. Integr Biol (Camb). 2011;3:803-815.

124. Smith PJ, Giroud M, Wiggins HL, et al. Cellular entry of nanoparticles via serum sensitive clathrin-mediated endocytosis, and plasma membrane permeabilization. Int J Nanomedicine. 2012;7:2045-2055.

125. Krajewska WM, Maslowska I. Caveolins: structure and function in signal transduction. Cell Mol Biol Lett. 2004;9:195-220.

126. Schnitzer JE, Oh P, Pinney E, Allard J. Filipin-sensitive caveolaemediated transport in endothelium: reduced transcytosis, scavenger endocytosis, and capillary permeability of select macromolecules. J Cell Biol. 1994;127:1217-1232.

127. Hillaireau H, Couvreur P. Nanocarriers' entry into the cell: relevance to drug delivery. Cell Mol Life Sci. 2009;66:2873-2896.

128. Swanson JA, Watts C. Macropinocytosis. Trends Cell Biol. 1995;5: 424-428.

129. Harush-Frenkel O, Rozentur E, Benita S, AltschulerY. Surface charge of nanoparticles determines their endocytic and transcytotic pathway in polarized MDCK cells. Biomacromolecules. 2008;9:435-443.

130. Damm EM, Pelkmans L, Kartenbeck J, Mezzacasa A, Kurzchalia T, Helenius A. Clathrin- and caveolin-1-independent endocytosis: entry of simian virus 40 into cells devoid of caveolae. J Cell Biol. 2005; 168:477-488.

131. Mayor S, Pagano RE. Pathways of clathrin-independent endocytosis. Nat Rev Mol Cell Biol. 2007;8:603-612.

132. dos Santos T, Varela J, Lynch I, Salvati A, Dawson KA. Effects of transport inhibitors on the cellular uptake of carboxylated polystyrene nanoparticles in different cell lines. PLoS One. 2011;6:e24438.

133. des Rieux A, Fievez V, Garinot M, Schneider YJ, Préat V. Nanoparticles as potential oral delivery systems of proteins and vaccines: a mechanistic approach. J Control Release. 2006;116:1-27.

134. Kamel AO, Awad GA, Geneidi AS, Mortada ND. Preparation of intravenous stealthy acyclovir nanoparticles with increased mean residence time. AAPS PharmSciTech. 2009;10:1427-1436.

135. Almeida AJ, Souto E. Solid lipid nanoparticles as a drug delivery system for peptides and proteins. Adv Drug Deliv Rev. 2007;59:478-490.

136. Innes NP, Ogden GR. A technique for the study of endocytosis in human oral epithelial cells. Arch Oral Biol. 1999;44:519-523. 
137. Nabeshi H, Yoshikawa T, Akase T, et al. Effect of amorphous silica nanoparticles on in vitro RANKL-induced osteoclast differentiation in murine macrophages. Nanoscale Res Lett. 2011;6:464.

138. Eliaz RE, Nir S, Marty C, Szoka FC Jr. Determination and modeling of kinetics of cancer cell killing by doxorubicin and doxorubicin encapsulated in targeted liposomes. Cancer Res. 2004;64:711-718.

139. Chen M, Gao S, Dong M, et al. Chitosan/siRNA nanoparticles encapsulated in PLGA nanofibers for siRNA delivery. ACS Nano. 2012;6:4835-4844.

140. Song J, Kahveci D, Chen M, et al. Enhanced catalytic activity of lipase encapsulated in PCL nanofibers. Langmuir. 2012;28:6157-6162.

141. Zhang J, Chen XG, Liu CS, Park HJ. Investigation of polymeric amphiphilic nanoparticles as antitumor drug carriers. J Mater Sci Mater Med. 2009;20:991-999.

142. Shi X, Thomas TP, Myc LA, Kotlyar A, Baker JR Jr. Synthesis, characterization, and intracellular uptake of carboxyl-terminated poly(amidoamine) dendrimer-stabilized iron oxide nanoparticles. Phys Chem Chem Phys. 2007;9:5712-5720.

143. Wang JJ, Zeng ZW, Xiao RZ, et al. Recent advances of chitosan nanoparticles as drug carriers. Int J Nanomedicine. 2011;6:765-774.

144. Georgieva JV, Kalicharan D, Couraud PO, et al. Surface characteristics of nanoparticles determine their intracellular fate in and processing by human blood-brain barrier endothelial cells in vitro. Mol Ther. 2011;19:318-325.

145. Baoum A, Dhillon N, Buch S, Berkland C. Cationic surface modification of PLG nanoparticles offers sustained gene delivery to pulmonary epithelial cells. J Pharm Sci. 2010;99:2413-2422.

146. de Salamanca AE, Diebold Y, Calonge M, et al. Chitosan nanoparticles as a potential drug delivery system for the ocular surface: toxicity, uptake mechanism and in vivo tolerance. Invest Ophthalmol Vis Sci. 2006;47:1416-1425

147. Roy S, Pal K, Anis A, Pramanik K, Prabhakar B. Polymers in mucoadhesive drug delivery system: a brief note. Des Monomers Polym. 2009; 12:483-495.

148. Talaei F, Azizi E, Dinarvand R, Atyabi F. Thiolated chitosan nanoparticles as a delivery system for antisense therapy: evaluation against EGFR in T47D breast cancer cells. Int J Nanomedicine. 2011;6:1963-1975.

149. Shuvaev VV, Ilies MA, Simone E, et al. Endothelial targeting of antibody-decorated polymeric filomicelles. ACS Nano. 2011;5: 6991-6999.

150. Kim J, Dadsetan M, Ameenuddin S, Windebank AJ, Yaszemski MJ, $\mathrm{Lu} \mathrm{L}$. In vivo biodegradation and biocompatibility of PEG/sebacic acid-based hydrogels using a cage implant system. J Biomed Mater Res A. 2010;95:191-197.

151. Nicolete R, dos Santos DF, Faccioli LH. The uptake of PLGA micro or nanoparticles by macrophages provokes distinct in vitro inflammatory response. Int Immunopharmacol. 2011;11:1557-1563.

152. Wang ZG, Hsiao BS, Zong XH, et al. Morphological development in absorbable poly(glycolide), poly(glycolide-co-lactide) and poly(glycolide-co-caprolactone) copolymers during isothermal crystallization. Polymer. 2000;4:621-628.

153. Niederman R, Zhang J, Kashket S. Short-chain carboxylic-acidstimulated, PMN-mediated gingival inflammation. Crit Rev Oral Biol Med. 1997;8:269-290.

154. Mitra S, Gaur U, Ghosh PC, Maitra AN. Tumour targeted delivery of encapsulated dextran-doxorubicin conjugate using chitosan nanoparticles as carrier. J Control Release. 2001;74:317-323.

155. Loh JW, Yeoh G, Saunders M, Lim LY. Uptake and cytotoxicity of chitosan nanoparticles in human liver cells. Toxicol Appl Pharmacol. 2010;249:148-157.

156. Moghimi SM, Symonds P, Murray JC, Hunter AC, Debska G, Szewczyk A. A two-stage poly(ethylenimine)-mediated cytotoxicity: implications for gene transfer/therapy. Mol Ther. 2005;11: 990-995.

157. Gupta KC, Kumar P, Swami A, Pathak A, Inventors. Novel crosslinked pei nanoparticle based transfection agents for delivery of biomolecules. United States Patent US20100029750 A1. February 4, 2010.
158. Goyal R, Tripathi SK, Tyagi S, et al. In vitro and in vivo evaluation of linear polyethylenimine nanoparticles. J Biomed Nanotechnol. 2011;7:52-53.

159. Tag Ko Y, Kale A, Hartner W, Papahadjopoulos-Sternberg B, Torchilina V. Self-assembling micelle-like nanoparticles based on phospholipidpolyethyleneimine conjugates for systemic gene delivery. J Control Release. 2009;133:132-138.

160. Xiao J, Duan X, Yin Q, Chen L, Zhang Z, Li Y. Low molecular weight polyethylenimine-graft-Tween 85 for effective gene delivery: synthesis and in vitro characteristics. Bioconjug Chem. 2012;23:222-231.

161. Fernandez-Carballido A, Pastoriza P, Barcia E, Montejo C, Negro S. PLGA/PEG-derivative polymeric matrix for drug delivery system applications: characterization and cell viability studies. Int J Pharm. 2008;352:50-57.

162. Liu J, Jiang Z, Zhang S, Saltzman WM. Poly(omega-pentadecalactoneco-butylene-co-succinate) nanoparticles as biodegradable carriers for camptothecin delivery. Biomaterials. 2009;30:5707-5719.

163. Deschamps AA, Grijpma DW, Feijen J. Poly(ethylene oxide)/ poly(butylene terephthalate) segmented block copolymers: the effect of copolymer composition on physical properties and degradation behavior. Polymer. 2001;42:9335-9345.

164. Gibas I, Janik H. Review: synthetic polymer hydrogels for biomedical applications. Chem Chem Technol. 2010;4:297-304.

165. Batheja P, Sheihet L, Kohn J, Singer AJ, Michniak-Kohn B. Topical drug delivery by a polymeric nanosphere gel: formulation optimization and in vitro and in vivo skin distribution studies. J Control Release. 2011;149:159-167.

166. Errico C, Bartoli C, Chiellini F, Chiellini E. Poly(hydroxyalkanoates)based polymeric nanoparticles for drug delivery. J Biomed Biotechnol. 2009;2009:571702.

167. Moebus K, Siepmann J, Bodmeier R. Alginate-poloxamer microparticles for controlled drug delivery to mucosal tissue. Eur J Pharm Biopharm. 2009;72:42-53.

168. Li X, Yang Z, Yang K, et al. Self-assembled polymeric micellar nanoparticles as nanocarriers for poorly soluble anticancer drug ethaselen. Nanoscale Res Lett. 2009;4:1502-1511.

169. Rai B, Teoh SH, Hutmacher DW, Cao T, Ho KH. Novel PCL-based honeycomb scaffolds as drug delivery systems for rhBMP-2. Biomaterials. 2005;26:3739-3748.

170. Helle J, Barr J, Ng SY, et al. Development and applications of injectable poly(ortho esters) for pain control and periodontal treatment. Biomaterials. 2002;23:4397-4404.

171. Gunatillake PA, Adhikari R. Biodegradable synthetic polymers for tissue engineering. Eur Cell Mater. 2003;5:1-16.

172. Bernkop-Schnurch A, Dunnhaupt S. Chitosan-based drug delivery systems. Eur J Pharm Biopharm. 2012;81:463-469.

173. Thanou M, Verhoef JC, Junginger HE. Oral drug absorption enhancement by chitosan and its derivatives. Adv Drug Deliv Rev. 2001;52:117-126.

174. Bhattacharjee S, Ershov D, Fytianos K, et al. Cytotoxicity and cellular uptake of tri-block copolymer nanoparticles with different size and surface characteristics. Part Fibre Toxicol. 2012;9:11.

175. Mihai R, Florescu IP, Coroiu V, Oancea A, Lungu M. In vitro biocompatibility testing of some synthetic polymers used for the achievement of nervous conduits. J Med Life. 2011;4:250-255.

176. Bertram JP, Jay SM, Hynes SR, Robinson R, Criscione JM, Lavik EB. Functionalized poly(lactic-co-glycolic acid) enhances drug delivery and provides chemical moieties for surface engineering while preserving biocompatibility. Acta Biomater. 2009;5:2860-2871.

177. Hu YL, Qi W, Han F, Shao JZ, Gao JQ. Toxicity evaluation of biodegradable chitosan nanoparticles using a zebrafish embryo model. Int J Nanomedicine. 2011;6:3351-3359.

178. da Silva LC, Garcia T, Mori M, et al. Preparation and characterization of polysaccharide-based nanoparticles with anticoagulant activity. Int J Nanomedicine. 2012;7:2975-2986. 
International Journal of Nanomedicine

Dovepress

\section{Publish your work in this journal}

The International Journal of Nanomedicine is an international, peerreviewed journal focusing on the application of nanotechnology in diagnostics, therapeutics, and drug delivery systems throughou the biomedical field. This journal is indexed on PubMed Central, MedLine, CAS, SciSearch ${ }^{\circledR}$, Current Contents ${ }^{\circledR} /$ Clinical Medicine,
Journal Citation Reports/Science Edition, EMBase, Scopus and the Elsevier Bibliographic databases. The manuscript management system is completely online and includes a very quick and fair peer-review system, which is all easy to use. Visit http://www.dovepress.com/ testimonials.php to read real quotes from published authors.

Submit your manuscript here: http://www.dovepress.com/international-journal-of-nanomedicine-journal 